\title{
Cocaína prenatal y conducta materna en la emocionalidad y el consumo de cocaína en ratones adultos
}

\author{
Santacruz, Ma del Pilar \\ Centro de Estudio e Investigaciones sobre Adicciones y Violencia. Facultad de Psicología. Universidad Católica de Colombia \\ Enviar correspondencia: \\ María del Pilar Santacruz. mpsanta@hotmail.com
}

\section{RESUMEN}

Se analizaron los efectos de la cocaína $30 \mathrm{mg} / \mathrm{kg}$ (s.c.) prenatal (gestación, día 1- 21) y de la conducta materna (madre biológica /nodriza) sobre la emocionalidad y el consumo voluntario de cocaína $30 \mathrm{mg} / \mathrm{kg}$, en ratones adultos. Después del parto cada madre crió cuatro hijos biológicos y adoptó cuatro (dos hembras y dos machos, en cada grupo). En la $5^{\text {a }}$ semana de edad, se evaluó la emocionalidad de los hijos tratados prenatalmente, seguido de la ingesta de cocaína $(30 \mathrm{mg} / \mathrm{kg})$ siete días y nuevamente la emocionalidad. En la segunda evaluacion, las hembras, se mostraron más ansiosas, consumiendo mas agua y explorando menos. La cocaína (30 mg/ $\mathrm{kg}$ ) prenatal influyó más que las condiciones de crianza en la emocionalidad a mediano plazo en las hembras.

Palabras clave: cocaína, ratones, exposición prenatal, evaluación, grupo control.

\section{SUMMARY}

The effects of prenatal cocaine $30 \mathrm{mg} / \mathrm{kg}$ (s.c.) were analyzed (gestation, day 1-21) and the maternal behavior (biological mother /wet nurse) on the emotional behavior and the voluntary cocaine consumption $30 \mathrm{mg} / \mathrm{kg}$, in adult mice. After of the birth each mother raised four biological mice and adopted four (two female and two males, in each group). In 5th week, the prenatal treated mice, the emotional behavior was evaluated, followed by the cocaine intake $(30 \mathrm{mg} / \mathrm{kg})$ for seven days and again the emotional behavior was evaluated. In the second evaluation, the females, were shown more anxious, consuming more water and exploring less. The prenatal cocaine $(30 \mathrm{mg} / \mathrm{kg}$ ) influence more the emotional behavior than the maternal behavior in the average term of the females.

Key words: cocaine, mice, prenatal consumption, control group.
$\mathbf{L}$ a Conducta Materna (CM) agrupa toda una serie de comportamientos encaminados al cuidado de la hembra hacia sus crías, y es una de las conductas afiliativas de mayor importantancia debido al estrecho vinculo madre/hijo que se dá en los mamíferos principalmente, desde épocas tempranas de vida, ya que esta conducta se inicia desde el momento mismo de la concepción, debido a que las crías, obtienen de su madre componentes biológicos y comportamentales fundamentales, que las capacita para el manejo de su ambiente y su posterior adaptación.

Teniendo en cuenta este estrecho vinculo madre/ hijo, se observa como el comportamiento general de la madre tiene una incidencia decisiva en desarrollo de su hijo y su posterior adaptación, porque a la clara influencia biológica, se suma la comportamental dado que el bebé inicia con su madre las primeras interacciones sociales desde periodos neonatales. Durante la gestación la relación de gran interdependencia entre la madre y el feto, se apoya principalmente en la placenta, órgano materno mediante el cual le trasmite a su hijo los nutrientes (y las drogas), la secreción hormonal, la inmunidad y el metabolismo de ciertas sustancias, posterior al parto, en períodos neonatales esta dependencia continua y es en esta época donde se acentúa la importancia de la conducta materna porque dá lugar a las primeras interacciones sociales, las que se van ampliando en la medida que los hijos exhiben comportamientos que les permiten una mayor autonomía, así los hijos se van independizando de su madre y paulatinamente se va debilitando este vínculo. De tal forma que la relación madre/hijo en épocas tempranas de la vida de un individuo cobra vital importancia para el posterior desarrollo de los sujetos.

Por estas razones se ha encontrado reiteradamente que madres con problemas de adaptación influyen negativamente en el desarrollo del bebe potenciando las probabilidad que ellos padezcan o desarrollen pro- 
blemas de comportamiento similares al de sus madres, los que se manifiestan en diferentes etapas de su vida. Así madres crónicamente deprimidas, quienes cuidaban a sus infantes desde la infancia temprana (relación madre/hijo de los 24 a los 42 meses), correlacionaron significativamente con bajo desempeño académico, conductas problema en el preescolar, en la escuela elemental y el bachillerato, con psicopatología y disociación en la adolescencia (Field,1998). De igual forma se observó con las madres que padecían alguna enfermedad psiquiátrica y sus hijos quienes presentaban depresión, desorden de pánico y desorden obsesivo-compulsivo, en adolescentes o adultos. (Weinberg y Tronick, 1998). Así se observa que los patrones de comportamiento desadaptativos que exhiben los hijos son el producto de la interacción entre el individuo y su ambiente, del cual la relación madre/hijo es una parte fundamental. (Carlos, 1998).

Teniendo en cuenta la gran importancia de la relación madre/hijo, desde el momento de la concepción, muchos profesionales de la salud se han enfocado en prevenir los posibles efectos teratogénicos que puede causar el consumo materno de drogas de diversa índole, porque ante el consumo materno, el feto sufre peligrosamente los resultados de esta conducta por los problemas médicos y obstétricos, que son el resultado directo de la sustancia que abusan y del estilo de vida de estas madres, el cual se caracteriza por aislamiento social, mala nutrición, promiscuidad, hábitos higiénicos deficientes y el policonsumo de drogas. El abuso materno de drogas en época gestacional tiene efectos somáticos y neuroconductuales devastadores para el recién nacido y pueden perdurar por el resto de la vida, (Weintraub, Bental, Olivan y Rotschild, 1998)

En EUA las mujeres ocupan del 34\% de los drogodependientes y de estas el 11-24\% están en etapa gestacional, con la posibilidad de la subestimación de estos datos, ya que son tomados de los hospitales o de los casos en los que interviene la policía, además existe presión social para negar el abuso de alguna sustancia en gestación (Jansson, Svikis, Lee, Paluzz, Rutligiano y Hackerman, 1996). En Colombia no existen datos relacionados con esta problemática, pero si se tiene en cuenta la información arrojada por algunos estudios, se podría predecir un alto número de complicaciones, debido a que el rango de edad de mayor incremento de consumo en mujeres es de 15 a 35 años, etapa de fertilidad femenina. (Estudio Nacional sobre el Consumo de Sustancias Psicoactivas, 1992; Universidad de Antioquía, 1987; Profamilia Bogotá, 1992; El Ministerio de Salud,1993; Posada y Torres, 1995; Pérez y Correa, 1994; Rodríguez y Duque, 1993).

Kosofky (1998) encontró que la exposición gestacional a drogas pueden causar un serio compromiso en el desarrollo psicofisiológico de los infantes. El cigarrillo se ha asociado con parto prematuro y con nume- rosas complicaciones obstétricas, placenta abrupta, aborto o bajo peso de los productos al nacer (Jansson, Svikis, Lee, Paluzz, Rutligiano y Hackerman,1996). Los opiáceos, con el síndrome de abstinencia neonatal, que incluye insomnio y miedo permanente además de otros síntomas de irritabilidad cerebral. Las benzodiacepinas pueden causar dimorfismo fetal (incluyendo microcefalia) daños neurológicos y conductuales además de síntomas de abstinencia neonatal. Las anfetaminas con disforia y agitación neonatal también como lasitud a largo plazo y modorra o somnolencia que puede resultar en una alimentación pobre y desnutrición. La exposición fetal a la marihuana puede causar problemas en el sistema visual y daños en la memoria verbal que se evidencia desde los dos años de edad. El alcohol prenatal causa síntomas de abstinencia neonatal, conductas desadaptativas en el niño y el síndrome alcohólico fetal (incluyendo microcefalia); el consumo materno de alcohol es una de las causas mas comunes del retardo mental. La exposición a la cocaína in útero se relaciona con irritabilidad cerebral, el perímetro encefálico reducido, pobre desarrollo mental y daños a largo plazo en el cerebro del neonato, anormalidades morfológicas fetales y en el Sistema Nervioso Central, déficits neurocomportamentales, alteraciones en el sistema genitourinario y cardiovascular, lo que se ha relacionado a los efectos vasoespásticos de la cocaína (Chasnoff, 1992); también se ha encontrado dificultad en modular la atención, deficiencias en la excitación y en la habituación, impulsividad, déficits notables en el aprendizaje y grandes dificultades para sostener fuertes vínculos afectivos, retardo en el desarrollo semántico temprano, caracterizado por un repertorio pobre desde los dos años de vida (Bland-Stewart, Seymour, Beeghly y Frank, 1998; Chasnoff, 1992; Kosofsky, 1998)

El abuso materno de drogas en época gestacional tiene efectos somáticos y neuroconductuales devastadores y perdurables en los hijos, de ahí la importancia de que el tratamiento a esta problemática, incluya un fuerte cuidado posnatal temprano y sobre todo, es de vital importancia que los profesionales de la salud deben ante todo enfocarse en la prevención en la población de alto riesgo. (Weintraub, Bental, Olivan y Rotschild, 1998): Ios efectos del consumo materno están relacionados con numerosos factores de los cuales la intensidad de la exposición prenatal, es uno de los de mayor peso, aunque se ha observado que el enriquecimiento del ambiente posnatal o las características de este cuidado posnatal revierten o atenúan los efectos asociados con el abuso materno de las drogas. (Kosofsky, 1998; Matera, Warren, Moomjy, Find y Fox, 1990). Dentro de las caracterisitcas del ambiente posnatal, se incluye la Conducta Materna como un aspecto crucial en el desarrollo del infante.

Una estrategia muy útil para aclarar diversos factores relacionados con los desórdenes parentales, son 
los estudios psicobiológicos de la CM, en los mamíferos, porque permiten la caracterización de las drogas y sus efectos tóxicos sobre el desarrollo psicofisiológico y comportamental de los animales y humanos, elementos esenciales que guían al tratamiento encaminado al control de esta problemática (Larsson,1994; Rosenblatt, 1995).

Cladji, Tannenbaum, Sharma, Francis, Plotsky y Meaney (1998) estudiando la Conducta materna, encontraron que los ratones infantes que habían recibido mayor frecuencia de lamido, de aseo y arqueo de la espalda materno, muestran sustancialmente menos conductas de miedo en respuesta a la novedad comparada con los que tuvieron baja frecuencia de estas conductas, en adultos. El grupo de alta frecuencia, presentó un significativo incremento en la densidad de los receptores benzodiazepínicos en la amígdala y en el locus cereleus, mayor densidad de los receptores adrenérgicos alfa 2, en el locus cereleus y menor densidad de los receptores de la hormona liberadora de corticotropina en esta misma estructura. Lo que sugiere que el cuidado materno desde períodos neonatales altera el desarrollo de los sistemas neurales que median el miedo y sirve para programar las respuestas conductuales al estrés en el recién nacido, las se manifestaran posteriormente.

Teniendo en cuenta que el sistema opiaceo controla numerosas conductas afiliativas; Dutriez-Casteloot, Bernet, Dedieu, Croix, Laborie, Montel, Lesage, Beauvillain, Dupouy (1999) evaluaron la influencia de la exposición gestacional a morfina $(2 \times 10 \mathrm{mg} / \mathrm{kg}$ diarios desde los días 11 al 18 de gestación) en los hijos, quienes mostraron baja talla al nacer, la actividad de las glándulas adrenales reducida y un gran dimorfismo sexual. Además de niveles reducidos de adrenalina (A) y noradrenalina (NA) en las glándulas adrenales, pero incremento en los niveles circulantes de A en el plasma. Niesink, Vanderschuren, Van-Ree (1996) encontraron que $(30$ y $40 \mathrm{mg} / \mathrm{kg}$ ) de morfina no afecto la gestación, ni el desarrollo sensoriomotor de las crías; Incrementó el juego social, sin alterar su secuencia, ni las actividades no sociales. Se afecto la percepción de la analgesia, la conducta social, la sexual y la responsividad al estrés, también se observaron perturbaciones en la respuesta a los estimulantes. La exposición prenatal a la morfina afectó el refuerzo y la motivación al juegocomo tambien el desarrollo del sistema opiáceo. Esto confirma los efectos negativos del consumo prenatal de opiáceos para el subsecuente funcionamiento psicofisiológico y bioquímico del infante.

Son numerosos los efectos de la exposición prenatal al alcohol, Domínguez, López, Chotro, Molina (1996); encontraron que la administración de alcohol 1, o 2 g/kg/día. a ratas Wistar no afecto los parámetros físicos materno/fetales y perinatales como el peso de la placenta, la talla del cordón umbilical. Pero si se encontró reducción del peso corporal de los recién nacidos, del tamaño del bulbo olfatorio, el de los hemisferios cerebrales y del cerebelo. Además se encontró modificada la responsividad posterior al consumo del alcohol, lo que habla de una subsensibilidad a los efectos del alcohol. Cortese, Krahl, Berman y Hannigan (1997) encontraron que la exposición prenatal al alcohol (3 g/kg/día) no tenia efectos sobre el aprendizaje pero $5 \mathrm{~g} / \mathrm{kg} /$ día disminuía el aprendizaje en los machos, el que se correlacionaba con un decremento de la actividad electroencefalográfica, ondas teta clase II (relacionadas con el procesamiento de información) en el hipocampo. La exposición al alcohol in útero (10 g/kg/día) en ratas producía disfunciones a largo plazo en la función inmune, por lo tanto una disminución de la resistencia a las infecciones, lo que se ha encontrado en los estudios con animales y humanos.(Yirmiya, Tio, Taylor, 1996) Tambien encontraron que la exposición in útero al etanol incrementaba la hipotermia que le seguía a la administración i.p. de etanol $(2 \mathrm{~g} / \mathrm{kg}$ ) en ratas macho y hembras Sprague-Dawley y la manipulación posnatal temprana disminuyó este incremento; los machos y las hembras manipulados mostraron menos hipotermia en general que los no manipulados. La manipulación posnatal temprana aceleró el retorno a la temperatura normal después de la inyección de etanol $(2.0 \mathrm{~g} / \mathrm{kg}$, i.p.), pero no afecto las respuestas de la corticosterona (CORT) al etanol (1.5 $\mathrm{g} / \mathrm{kg}$, i.p.). Las hembras y machos manipulados exhibieron mayores niveles de CORT en comparación a las no manipulados y se incrementó significativamente la afinidad de los ligandos a los receptores de los glucocorticoides clase II en los sujetos manipulados. La manipulación temprana elimina el incremento de las respuestas de la CORT al estrés de restricción, pero no afecta la prolongación de la respuesta de CORT. Todos estos datos indican que la manipulación temprana puede modular o atenuar algunos, pero no todos los efectos adversos de la exposición prenatal al etanol sobre el crecimiento del recién nacido, sus respuestas psicofiológicas y su responsividad en general. (Weinberg, Kim, Kwon y Yu, 1995)

Chen, Andersen, West (1994) analizaron el daño fetal causado por la exposición interactiva de cocaína (40, o $60 \mathrm{mg} / \mathrm{kg}$ ) y alcohol $(0,3.3$, o $4.5 \mathrm{~g} / \mathrm{kg})$ en época gestacional, en ratas Sprague-Dawley. La droga de mayor letalidad fué la cocaína y la administración concurrente de alcohol y cocaína incrementó la mortalidad por lesiones en el sistema cardiovascular. El alcohol redujo significativamente el peso total del cerebro, específicamente del cerebro anterior, cerebelo y tallo cerebral, la cocaína no tuvo efectos sobre estas estructuras.

La exposición prenatal a la cocaína $(20 \mathrm{mg} / \mathrm{kg}$ via oral), dos veces diarias desde el día 40-102 de embarazo (E40-E102), en monos reshus, alteró significativamente la formación de las láminas en la corteza cerebral, en algunos casos se encontraron completa- 
mente mezcladas entre sí, mostrando diversas clases de células en la materia blanca y en las láminas corticales IV, V y VI; además el número de células fue mucho más bajo en estos sujetos, y se observó una disminución considerable de las fibras gliales, en las láminas corticales superiores. (Lidow, 1995)

Goodwin, Bliven, Kuhn, Francis y Spear (1997) encontraron que la exposición prenatal a cocaína en ratas alteraba la emocionalidad posterior o las respuestas conductuales al estrés en adultos. Se analizaron las respuestas fisiológicas y conductuales a una única vs. repetida exposición al estresor. Se les administró a las hembras diariamente 40 mg/kg cocaína (C40) desde el día 8-20 del período gestacional. Se encontró que la exposición prenatal a la cocaína produce más tiempo en congelamiento en las ratas macho y hembra que en las del grupo control, cuando se les aplicaba un choque eléctrico. Sin embargo no se encontraron diferencias en ninguna de las medidas fisiológicas observadas, como los niveles de la hormona adrenocorticotrófica (ACTH) en el núcleo paraventricular del hipotálamo (PVN), en el núcleo supraóptico y en locus cerelus. Esto plantea la necesidad de hacer más investigaciones que exploren los efectos de la cocaína prenatal y la emocionalidad observada en la respuesta al estrés.

Hecht, Spear y Spear (1998) encontraron alteraciones en la eficacia del refuerzo por la exposición fetal a la cocaína $(40 \mathrm{mg} / \mathrm{kg} / 3 \mathrm{cc})$ en ratas macho adultos desde el día 8-20. Los adultos mostraron incremento en el palanqueo cuando el reforzador era la autoadministración de cocaína intravenosa en un programa de razón fija 5 (FR-5), y decrementaron el palanqueo en un programa de razón progresiva (PR). Hughes, Donohue, Dow-Edwards (1996) con la exposición prenatal a la cocaína (30 o 60 mg/kg/día) intragástricamente (i.g.) durante el día 8-22 de la gestación, encontraron disminución en la amplitud del reflejo de sobresalto en los adultos, principalmente en las hembras y las anfetaminas no alteraban el tiempo de reacción en las ratas expuestas prenatalmente a la cocaína.

Goodwin, Bliven, Kuhn, Francis y Spear (1997) encontraron que la exposición prenatal a cocaína 40 $\mathrm{mg} / \mathrm{kg}$ alteraba la Conducta Emocional de las ratas adultas, produciendo máyor tiempo de congelamiento en las ratas macho y hembra, cuando se les aplicaba un choque eléctrico. Pero no se encontraron diferencias en los niveles de la hormona adrenocorticotrófica (ACTH) en el núcleo paraventricular del hipotálamo (PVN), en el núcleo supraóptico y en locus cerelus entre los grupos.

D'amato, Cabid, Ventura y Orsini (1998) investigaron el rol de la CM sobre los efectos a largo plazo de la manipulación posnatal. Se trató a las madres con Clordiazepoxide (5 mg/kg), (antiansiogénico) diariamente mientras se movía la camada del nido. El tratamiento farmacológico a las madres no afecto ni la CM ni el llanto de los hijos producido por la separación de sus madres. Las madres tratadas con CDZ fueron menos responsivas con sus crías cuando se reunían después de las separaciones diarias. El ratón manipulado durante el desarrollo posnatal fue más explorador y menos ansioso que el no manipulado, aunque este efecto no se observó en los hijos de la madres tratadas con la CDZ. La interacción madre/hijo positiva, seguida de la separación, juega un importante papel en determinar los efectos de las manipulaciones posnatales sobre la emocionalidad en adultos.

A través de los estudios anteriores se ha visto como el consumo materno de alguna droga lesiona el futuro funcionamiento psicofisiológico, bioquímico y conductual del infante, porque está sometido a este imbalance de la madre, quien le trasmite componentes biológicos y comportamentales que pueden lesionar permanentemente el comportamiento de sus hijos; aun no se ha podido establecer el peso de estos factores en el futuro funcionamiento de los hijos (biológicos o conductuales) para la exhibición de los posteriores comportamientos desadaptativos de los hijos de madres adictas, por lo que existe el paradigma de "la adopción cruzada" dentro de los modelos animales, el cual se hga visto muy útil para separar la influencia biológica y/o genética de la comportamental de la madre hacia sus crías. Consiste en que las madres de un grupo adoptan una parte o la totalidad de los hijos de otra madre; y de esta forma se puede obtener información acerca de cuales de los factores ambientales y biológicos tienen mayor incidencia en el futuro funcionamiento emocional y conductual de los hijos. (Dess y Minor, 1992; Brewer, 1996)

Goluldsborough, Black, Johnson y Asthon (1998) mediante este paradigma, el de" la adopción cruzada" compararon la influencia genética de la comportamental en el aprendizaje del control de su respuesta antihipertensiva. Ratas Hipertensas Espontáneas (SHR) adoptaron crías de Wistar Kyoto (WKY), quienes en adultos bajan permanentemente la presión sanguínea y estas a su vez adoptaron crías de SHR. Las crías SHR adoptadas por las WKY, disminuyeron significativamente su presión arterial comparadas con las crías SHR mantenidas con su madre biológica. Los efectos antihipertensivos de la crianza a los hijos de SHR con las madres WKY madres, destaca la importancia del cuidado materno en el aprendizaje del control de la respuesta antihipertensiva.

Kurnianto, Shinjo, y Suga (1998) por medio de la adopción cruzada evaluaron las variables prenatales y posnatales en el peso corporal en la 1a, 6a y 10a semana de edad en las crías de ratónes CF1y Yk. El mayor peso corporal se encontró en las crías CF1 mantenidos con su madre biológica, seguido por los infantes CF1 adoptados por las Yk, los siguientes fueron los hijos YK con su madre biológica, lo que indica que las variables maternas prenatales fueron más 
importantes que las posnatales en el peso corporal en todas las edades examinadas.

Cuatro macaca rhesus (macaca mulata) adoptaron un neonato abandonado. Las madres iniciaron mas contacto con sus hijos y estos tuvieron mayor contacto materno y permanecieron más tiempo en la posición ventro-ventral en comparación a los adoptados; estas variaciones se deben posiblemente a la conducta materna diferencial que captan sus hijos y favorece un circuito de retroalimentación de las conductas de cuidado entre los hijos biológicos y su madre. Los hijos adoptados ganaron peso más lentamente que los biológicos y las madres que adoptaron tuvieron menos hijos en el siguiente parto. (Ellsworth y Andersen, 1997). Este estudio resalta la constante interacción madre/hijo a nivel genético, biológico y comportamental.

Teniendo en cuenta que la conducta materna, son todos los comportamientos de la madre hacia sus crías para capacitarlas para una posterior adaptación, es importante analizar la influencia del consumo gestacional de cocaína a nivel biológico y comportamental (mediante el modelo de la dopción cruzada") en la Conducta Emocional (CE) de los hijos adultos. Se ha tomado esta conducta porque describe la capacidad de supervivencia de las especies, debido a que evalúa la efectividad de minimizar los riesgos de muerte o extinción, en cada una de las situaciones de conflicto, se estudia a través del análisis de la conducta exploratoria en un ambiente novedoso, (Clement y Chapouthier, 1998; Bernard y Bandler, 1998; Hendrie, Weiss y Eilam,1996; Hendrie, Eilam, Weiss, 1997) porque el indagar un ambiente novedoso implica un incremento en los riesgos de predación, se basa en la preferencia por los lugares oscuros y áreas protegidas de los roedores, la que puede modificarse por agentes ansiolíticos o ansiogénicos (Clement y Chapouthier, 1998). Para el análisis de la conducta exploratoria generalmente se utilizan el tablero de agujeros y el laberinto en cruz, porque estos modelos no utilizan estímulos aversivos que alteran la bioquímica del sujeto y el subsecuente efecto de la droga. (Flint, Corley, DeFries, Fulker, Gray, Miller y Collins, 1995; Rodgers, Cao, Dalvi y Holmes, 1997; Santacruz y col., 1998; Ruarte, Orofino, Alvarez, 1997; Prasad, Henry y Prasad, 1996).

El análisis de la conducta exploratoria en complemento con la ingesta de agua, provee una información detallada de la CE, porque el sabor, la emocionalidad y la vulnerabilidad comparten los mismos mecanismos. (Dess y Minor, 1996). Y reiteradamente se ha encontrado que la ingesta tiene una gran interacción con los procesos afectivos como el miedo y el estrés (Dess, 1991). Porque se ha encontrado que los sujetos expuestos a choques intermitentes, alteran la distribución y la frecuencia de la alimentación, o del consumo de agua, de forma correlacionada con un estado persistente de miedo y ansiedad, (Dess y Minor, 1996). Adicionalmente las ratas de menor peso corporal son más responsivas, presentan mas chillidos o vocalizaciones de estrés que las ratas de mayor peso corporal, después de la exposición a un choque inescapable (Dess y Chapman, 1990). Por lo que la combinación de los paradigmas de la conducta emocional con el de "la elección libre de dos botellas", permite la evaluación exhaustiva de la Emocionalidad, correlacionandola con el consumo de agua, adicionalmente brinda información sobre el consumo voluntario de una droga.

En el modelo de "la elección libre de dos botellas", mediante el cual se logra examinar objetivamente la ingesta, se colocan en acceso libre en la caja-hogar de los roedores, dos botellas una con agua y la otra con la droga que se quiera probar. (Wilson, Neil y Costall, 1996; Ritz, Garcia, Protz, Rael y George, 1994) además permite establecer similitudes con el consumo en humanos (Wilson, Neil y Costall, 1995) examinando de una forma sencilla y objetiva el consumo voluntario de líquido (Wilson, Neil y Costall, 1996). Y provee de índices básicos para evaluar el papel de diferentes condiciones de mantenimiento para las respuestas conductuales a la droga. (Smith, Neil y Costall, 1996; Smith, Neill y Costall, 1997). De tal forma que la combinación de estos tres modelos permiten aclarar la influencia de la adiccion gestacional materna en la Conducta emocional y en el consumo voluntario de cocaína, de manera sencilla y objetiva.

Teniendo en cuenta las diversas alteraciones psicofisologicas causadas por la exposición prenatal a cocaína, es importante explorar la influencia de la administración prenatal de cocaína $(30 \mathrm{mg} / \mathrm{kg}$ ) y separar los efectos biológicos de los conductuales que trasmite la madre a sus crías (lo que permite el modelo de la adopción cruzada) observando estos efectos sobre la Conducta Emocional de los hijos, (conducta exploratoria) en complemento con la ingesta de agua, y evaluar la probabilidad de exhibir comportamientos adictivos en comparación a los hijos de madre no adictas, (se estima que la proporción es 3:1 en humanos); así la compleja interacción entre el sistema biológico y el ambiental, se puede evaluar mediante modelos animales (lo que es imposible en humanos) y se lograria aclarar el peso de estos factores en determinados problemas comportamentales que se observan en los hijos de madres adictas; el analizar la "predisposición de los hijos de estas madres a exhibir conducta adictiva se puede hacer mediante el modelo de " elección libre de dos botellas". El esclarecimiento de los factores relacionados con la conducta adictiva contribuye a idear estrategias de tratamiento y prevención.

De esta forma el Objetivo del presente estudio fue observar los efectos de la administración prenatal de cocaína $(30 \mathrm{mg} / \mathrm{kg})$ y la influencia de la conducta materna -madre biológica y nodriza- sobre la conducta emocional, a mediano ( $5^{\mathrm{a}}$ semana de vida) y largo plazo ( $7^{a}$ semana), la ingesta de agua y el consumo 
voluntario de hidrato de cocaína $(30 \mathrm{mg} / \mathrm{kg})$ en las hembras y machos adultos.

\section{MÉTODO}

\section{Diseño}

Diseño experimental jerárquico, con dos tratamientos prenatales administración crónica de cocaína $(0$ y $30 \mathrm{mg} / \mathrm{kg}$ ) y dos condiciones de crianza; madres biológicas y nodriza en hembras y machos. La combinación de estas variables resultó en ocho grupos a saber:

\section{Emocionalidad}

Tablero de agujeros: Caja de madera de $40 \times 40 \times$ 30 con la base dividida en 16 cuadros de $10 \times 10 \mathrm{~cm}$, con cuatro agujeros de tres $\mathrm{cm}$ de diámetro cada uno, ubicados en el área central, en donde se tienen en cuenta los siguiente parámetros:

Locomoción periférica: Desplazamiento del sujeto por los doce cuadros laterales de la caja

Locomoción central: Numero de cruces por la zona central del tablero

Autoaseo: El sujeto se limpia su cuerpo mediante su patas delanteras y boca
Madre Experimental / Hijo Grupo Experimental Macho Madre Experimental / Hijo Grupo Experimental Hembra Madre Experimental / Hijo Grupo Control Macho Madre Experimental / Hijo Grupo Control Hembra
Madre Control / Hijo Grupo Experimental Macho Madre Control / Hijo Grupo Experimental Hembra Madre Control / Hijo Grupo Control Macho Madre Control / Hijo Grupo Control Hembra

\section{Sujetos}

Se utilizaron 14 ratones hembra de la cepa C57 preñadas, divididas aleatoriamente en dos grupos siete para el experimental y siete para el control, una hembra del grupo experimental murió en el estudio, quedando para este grupo 6 hembras.

Después del parto se dejaron 8 infantes para cada madre, cuatro hembras y cuatro machos; los demás se sacrificaron, para "la adopción cruzada", se dejaron cuatro hijos biológicos y cuatro adoptados, dos hembras y dos machos en cada grupo. Asi cada madre crió dos hembras y dos machos, hijos biológicos y los mismos adoptados. De los 104 hijos tratados prenatalmente, 48 pertenecian al grupo experimental y 56 al control, estos se distribuian en cuatro grupos: hijos control criados, con sus madres (CNB), hijos experimentales, adoptados por hembras Control (CNA), hijos biológicos del grupo tratado con cocaína con sus madres (CCB), hijos del grupo control adoptados por hembras experimentales (CCA), con igual número de hembras y machos en cada grupo.

\section{Técnicas e Instrumentos}

Droga: Clorhidrato de cocaína (30 mg/kg)

Hidrato de cocaína $(30 \mathrm{mg} / \mathrm{kg}$ ) en una botella, cantidad diaria de consumo medida en $\mathrm{ml}$.

Agua: cantidad diaria de consumo de agua medida en $\mathrm{ml}$.

13 Parametros de emocionalidad en el tablero de agujeros y en el laberinto en cruz elevado
Erguidas: Posición vertical levantando sus patas delanteras y se queda sostenido en sus traseras

Entradas a los agujeros: Introducciones de la cabeza en uno de los agujeros ubicados en la base del tablero de agujeros.

Tiempo en los agujeros: Segundos que el sujeto deja su cabeza introducida en los agujeros

Excretas: Número de defecaciones

Laberinto en cruz: Un laberinto con dos brazos abiertos de $5 \times 30 \mathrm{~cm}$, dos cerrados de $5 \times 30 \times 30$ $\mathrm{cm}$, los brazos se conectan en cruz por una zona de 5 x 5 (Zona Neutra). El laberinto se eleva del piso $38 \mathrm{~cm}$, paradigma en el cual se evalùan los siguientes parámetros.

Entradas a los brazos abiertos: veces que el sujeto se introduce en los brazos sin paredes.

Entradas a los brazos cerrados: Veces que el sujeto se introduce en los brazos con paredes

Tiempo en los brazos abiertos. Segundos que el sujeto permanece en los brazos abiertos.

Tiempo en los brazos cerrados: Segundos que el sujeto permanece en los brazos con paredes.

Tiempo en zona neutra: Segundos que el sujeto permanece en la zona abierta y despejada donde inician los brazos abiertos y los cerrados

Numero de excretas: Es la frecuencia de bolos de defecación.

\section{Procedimiento}

Las 14 ratones hembras gestantes se dividieron aleatoriamente para el grupo control y el experimen- 
tal. Por medio del método doble-ciego se administraron las inyecciones diarias vía subcutánea (s.c.), desde el día 1 al 20 de gestación, (cocaína 30 mg/kg y Sol. Salina $0.09 \%$ )

Después del parto para "la adopción cruzada", cada hembra cuidaba cuatro hijos biológicos y cuatro adoptados (dos hembras y dos machos de cada grupo). El resto de los hijos se sacrificó. Para distinguir los tratados prenatalmente con el fármaco, se pintaban en el cuello y en la cola, cada $2^{\circ}$ día independientemente de la madre con quien permanecian (biológica o nodriza).

Después del destete se separaron las hembras de los machos de cada camada y se mantuvieron en condiciones gregarias. A las $5^{a}$ semana de edad se observó la conducta emocional individualmente, en el tablero de agujeros, seguido del laberinto en cruz, registrando los parámetros enunciados. Posteriormente se sometieron al test de "elección libre de dos botellas", donde permanecían "ad limitum" dos botellas en las cajas- habitación, una contenía agua y la otra cocaína 30mg/kg; se hizo una medición diaria del consumo por 7 días consecutivos, por sexo, camada y grupo. Se realizó la segunda observación de la CE, a las siete semanas de edad de la misma forma que en la primera.

Se utilizó una cámara de vídeo para incrementar la confiabilidad de las observaciones, la cual fué de 98\% como promedio total del estudio.

\section{RESULTADOS}

Para evaluar los diversos parámtros de la Conducta Emocional se utilizó el análisis de varianza multivariado y para la comparación entre la primera y la segunda observación de Conducta Emocional la prueba t de student de muestras pareadas. La ingesta voluntaria de agua y cocaína $30 \mathrm{mg} / \mathrm{kg}$ se examinó mediante el análisis de varianza multivariado.Para todos los datos se utilizó el paquete estadístico Stadistical Packet of Social Science (SPSS) versión 6.1

No se encontraron diferencias significativas en ninguno de los parámetros de la Conducta Emocional en la caja de agujeros y en el laberinto en cruz realizada a los sujetos a las cinco semanas de edad.

En la segunda evaluación de la CE se encontraron diferencias importantes, entre los grupos de tratamiento; a continuación se presentaran los diversos parámetros evaluados en estos dos paradigmas secuenciados, donde se describiran la media y la desviación estándar.

El tiempo en los agujeros, la frecuencia de entradas, de erguidas, excretas, la locomoción periférica y total, fue similar entre los grupos del estudio, pero el autoaseo y la locomoción central fueron significativamente diferentes.

Tabla 1. Parámetros evaluados en el tablero de agujeros

\begin{tabular}{|lcccccc|}
\hline Grupos & $\begin{array}{c}\text { Entradas } \\
\text { Agujeros }\end{array}$ & $\begin{array}{c}\text { Tiempo } \\
\text { Agujeros }\end{array}$ & Erguidas & Excretas & $\begin{array}{c}\text { Locomo. } \\
\text { Periférica }\end{array}$ & $\begin{array}{c}\text { Locomo. } \\
\text { Total }\end{array}$ \\
\hline CONTROL-BIOLO-MACHOS & $22,3 \pm 4.5$ & $26.0 \pm 21.0$ & $42,5 \pm 8.8$ & $2,5 \pm 3.5$ & $103.0 \pm 21.4$ & $145 \pm 15.9$ \\
CONTROL-BIOLO-HEMBRAS & $23,2 \pm 7.88$ & $31.0 \pm 18.0$ & $36,8 \pm 19.2$ & $1,7 \pm 3.6$ & $108.0 \pm 42.2$ & $156 \pm 46.7$ \\
CONTROL-ADOPT-MACHOS & $20.0 \pm 6.51$ & $26.0 \pm 16.0$ & $43.0 \pm 12.2$ & $2,3 \pm 2.9$ & $115.0 \pm 23.4$ & $163 \pm 32.4$ \\
CONTROLADOPT-HEMBRAS & $23,7 \pm 6.28$ & $26.0 \pm 8.9$ & $37.0 \pm 5.76$ & $2.0 \pm 1.8$ & $116.0 \pm 14.2$ & $166 \pm 10.9$ \\
COCA-BIOLO-MACHOS & $19,7 \pm 4.97$ & $21.0 \pm 4.2$ & $46,3 \pm 11.5$ & $3,7 \pm 1.9$ & $114.0 \pm 7.59$ & $152 \pm 11.5$ \\
COCA-BIOLO-HEMBRAS & $21,2 \pm 5.71$ & $23.0 \pm 8.3$ & $42,8 \pm 6.49$ & $1,5 \pm 1.8$ & $108.0 \pm 27.9$ & $156 \pm 37.4$ \\
COCA-ADOPTAD-MACHOS & $20,2 \pm 9.26$ & $20.0 \pm 8.3$ & $41,8 \pm 7.73$ & $1,6 \pm 1.1$ & $124.0 \pm 28.1$ & $172 \pm 39.9$ \\
COCA-ADOPTADO-HEMBRAS & $22.0 \pm 4.38$ & $26.0 \pm 9.1$ & $44,5 \pm 11.3$ & $1,7 \pm 1.6$ & $110.0 \pm 19.9$ & $148 \pm 24.0$ \\
\hline
\end{tabular}

Tabla 2. Análisis Factorial de los anteriores parámetros

\begin{tabular}{|lclcc|}
\hline GRUPOS & auotaseo & COMPARACIONES & F & SIG \\
\hline CONTROL-BIOLO-MACHOS & $2.0 \pm 0.63$ & COCAINAY SOL.SAL & 0.857 & 0.360 \\
CONTROL-BIOLO-HEMBRAS & $0,83 \pm 0.41$ & BIOLOGICOS-ADOPTADOS & 0.304 & 0.584 \\
CONTROL-ADOPT-MACHOS & $1,83 \pm 0.98$ & HEMBRAS- MACHOS & $\mathbf{4 . 5 1 5}$ & $\mathbf{0 . 0 3 9 *}$ \\
CONTROL-ADOPT-HEMBRAS & $1,17 \pm 0.98$ & COC,BIOL-ADPT-SOL.SAL & 1.424 & 0.239 \\
COCA-BIOLO-MACHOS & $1,33 \pm 0.82$ & COC, SOL,SALY HEMB.Y MAC & 2.988 & 0.091 \\
COCA-BIOLO-HEMBRAS & $1,50 \pm 0.84$ & BIOLOGIC.ADOPTADOS, HEMBRASY MACHOS & 0.063 & 0.803 \\
COCA-ADOPTAD-MACHOS & $1,20 \pm 1.1$ & COC-SOL.SAL,BIOL-ADOPT,HEMBY MACHOS & 0.799 & 0.376 \\
COCA-ADOPTADO-HEMBRAS & $1.0 \pm 0.63$ & & & \\
\hline
\end{tabular}

Las hembras en general exhibieron significativamente menor autoaseo que los machos. 


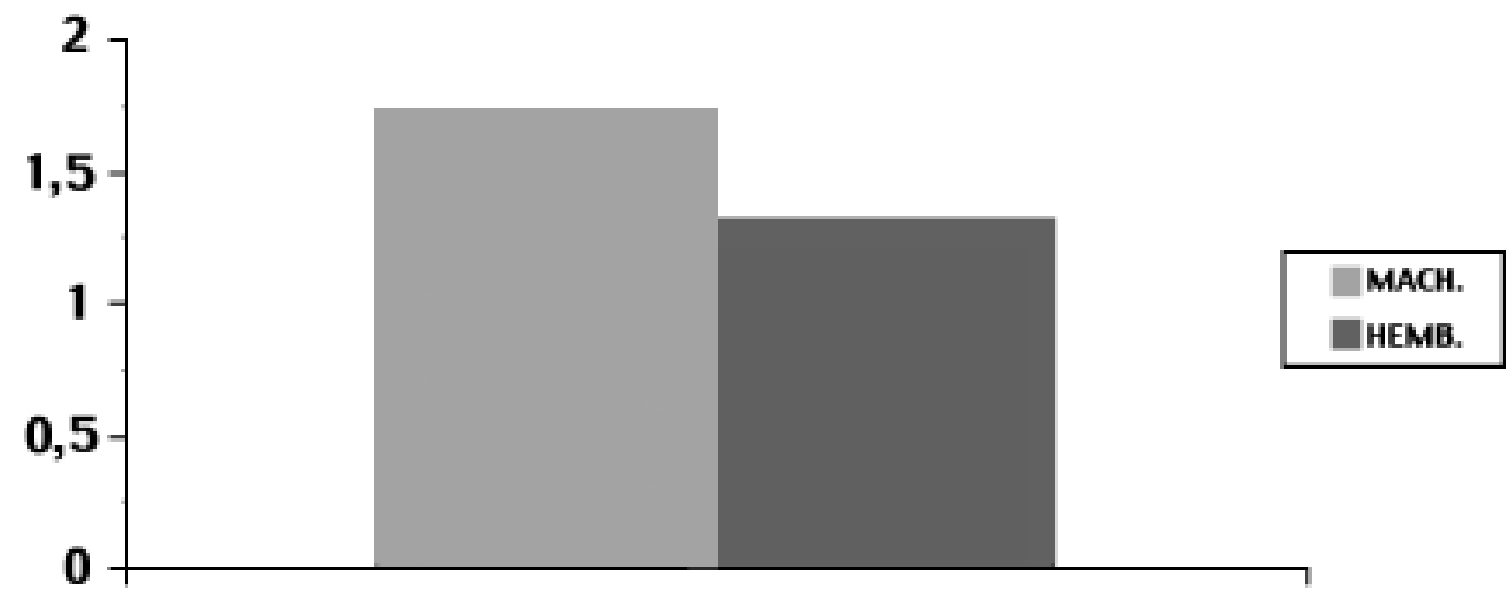

AUTOASEO

Tabla 3. Análisis Factorial de la Locomoción Central.

\begin{tabular}{|lclcc|}
\hline GRUPOS & Loc.CentI & COMPARACIONES & F & SIG \\
\hline CONTROL-BIOLO-MACHOS & $42,5 \pm 12.3$ & COCAINAY SOL.SAL & 3.524 & 0.067 \\
CONTROL-BIOLO-HEMBRAS & $48,7 \pm 5.99$ & BIOLOGICOS-ADOPTADOS & 0.057 & 0.813 \\
CONTROL-ADOPT-MACHOS & $47,5 \pm 10.6$ & HEMBRAS- MACHOS & 0.552 & 0.461 \\
CONTROL-ADOPT-HEMBRAS & $49,8 \pm 7.99$ & COC,BIOL-ADPT-SOL.SAL & 0.176 & 0.677 \\
COCA-BIOLO-MACHOS & $37,7 \pm 11.0$ & COC, SOL,SALY HEMB.Y MAC & 0.832 & 0.367 \\
COCA-BIOLO-HEMBRAS & $47,8 \pm 9.7$ & BIOLOGIC.ADOPTADOS, HEMBRASY MACHOS & $\mathbf{6 . 4 7 9}$ & $\mathbf{0 . 0 1 4 ^ { * }}$ \\
COCA-ADOPTAD-MACHOS & $47,8 \pm 14.0$ & COC-SOL.SAL,BIOL-ADOPT,HEMBY MACHOS & 1.858 & 0.180 \\
COCA-ADOPTADO-HEMBRAS & $38,3 \pm 6.31$ & & & \\
\hline
\end{tabular}

Se encontraron diferencias significativas de locomoción central entre las hembras y machos biológicos y adoptados, en la $F=6.479$ p >0.014 en las demás comparaciones no.

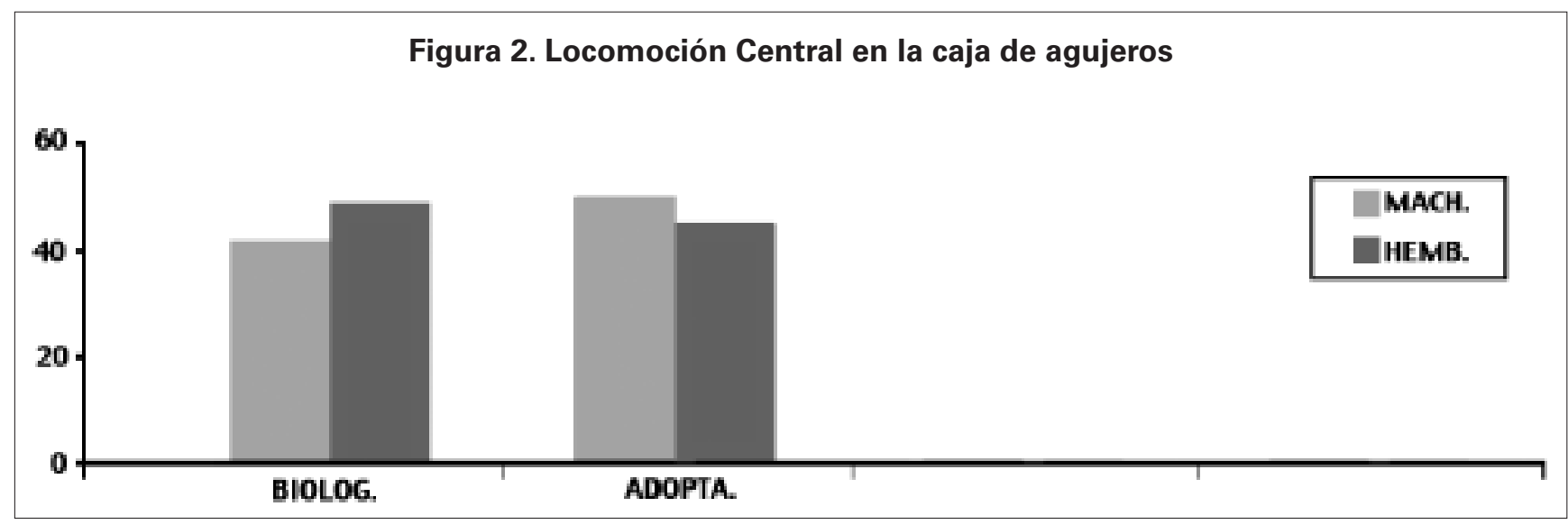

Se presenta la media de este parámetro observado en la caja de agujeros en la segunda medición de conducta emocional, en hembras y machos criados con sus madres biológicas y los adoptados. 
Tabla 4. Conducta Emocional en el laberinto en cruz

\begin{tabular}{|lccc|}
\hline GRUPOS & Tiempo Zona Neutra & Entradas Brazos Cerrados & Entradas Brazos Abiertos \\
\hline CONTROL-BIOLO-MACHOS & $122.0 \pm 49.38$ & $11.0 \pm 3.7$ & $9.0 \pm 4.82$ \\
CONTROL-BIOLO-HEMBRAS & $94.0 \pm 31.41$ & $11.0 \pm 4.3$ & $10.0 \pm 3.46$ \\
CONTROL-ADOPT-MACHOS & $117,2 \pm 36.26$ & $12.0 \pm 2.8$ & $8,67 \pm 2.94$ \\
CONTROL-ADOPT-HEMBRAS & $103.0 \pm 28.26$ & $13.0 \pm 4.3$ & $11.0 \pm 2.53$ \\
COCA-BIOLO-MACHOS & $98.0 \pm 35.06$ & $13.0 \pm 2.8$ & $12,3 \pm 3.78$ \\
COCA-BIOLO-HEMBRAS & $105,7 \pm 20.5$ & $15.0 \pm 3.8$ & $10,5 \pm 3.02$ \\
COCA-ADOPTAD-MACHOS & $111,6 \pm 37.25$ & $11.0 \pm 2.2$ & $10,8 \pm 2.59$ \\
COCA-ADOPTADO-HEMBRAS & $111,7 \pm 22.21$ & $13.0 \pm 1.6$ & $11,8 \pm 2.4$ \\
\hline
\end{tabular}

No se encontraron diferencias en las entradas a los brazos abiertos y cerrados y en el tiempo en zona neutra, aunque se observaron diferencias importantes en el tiempo de permanencia en los brazos cerrados y abiertos en las hembras y machos del grupo control y experimental.

Tabla 5. Análisis factorial del Tiempo de permanencia en brazos cerrados

\begin{tabular}{|lclcc|}
\hline GRUPOS & MEDIA \pm DES. ESTA & COMPARACIONES & F & SIG \\
CONTROL-BIOLO-MACHOS & $125.0 \pm 46.7$ & COCAINAY SOL.SAL & 0.948 & 0.335 \\
CONTROL-BIOLO-HEMBRA & $95,5 \pm 18.6$ & BIOLOGICOS-ADOPTADOS & 0.337 & 0.564 \\
CONTROL-ADOPT-MACHOS & $130.0 \pm 21.5$ & HEMBRAS- MACHOS & 0.945 & 0.336 \\
CONTROL-ADOPT-HEMBRA & $101.0 \pm 13.3$ & COC,BIOL-ADPT-SOL.SAL & 1.065 & 0.308 \\
COCA-BIOLO-MACHOS & $102.0 \pm 19.9$ & COC, SOL,SALY HEMB.Y MAC & $\mathbf{1 0 . 8 3 9}$ & $\mathbf{0 . 0 0 2 *}$ \\
COCA-BIOLO-HEMBRAS & $121.0 \pm 13.5$ & BIOLOGIC.ADOPTADOS, HEMBRASY ACHOS & 0.073 & 0.788 \\
COCA-ADOPTAD-MACHOS & $95,6 \pm 15.7$ & COC-SOL.SAL,BIOL-ADOPT,HEMBY ACHOS & 0.147 & 0.703 \\
COCA-ADOPTADO-HEMBRA & $98,7 \pm 5.65$ & & & \\
\hline
\end{tabular}

Se encontraron diferencias significativas entre el grupos de cocaína, vs sol. Salina entre las hembras y machos $F=10.839$ p: 0.002 .

Figura 3. Tiempo de permanencia en los brazos cerrados del laberinto en cruz

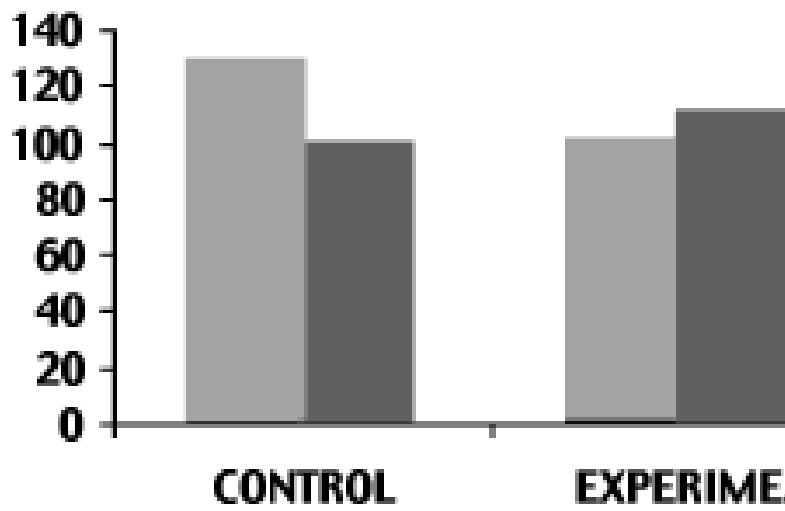

Se presenta el tiempo en los brazos cerrados de las hembras y los machos del grupo con tratamiento prenatal con sol.sal. y del de administración prenatal de cocaína $(30 \mathrm{mg} / \mathrm{kg}$ ) 


\section{Tabla 6. Tiempo en Brazos Abiertos}

\begin{tabular}{lclcc|}
\hline GRUPOS & TBA & COMPARACIONES & F & SIG \\
\hline CONTROL-BIOLO-MACHOS & $66,17 \pm 38.47$ & COCAINAY SOL.SAL & 0.681 & 0.414 \\
CONTROL-BIOLO-HEMBRAS & $113,8 \pm 43.93$ & BIOLOGICOS-ADOPTADOS & 0.042 & 0.839 \\
CONTROL-ADOPT-MACHOS & $66,67 \pm 18.42$ & HEMBRAS- MACHOS & 2.300 & 0.137 \\
CONTROL-ADOPT-HEMBRAS & $102,5 \pm 32.46$ & COC,BIOL-ADPT-SOL.SAL & 0.052 & 0.820 \\
COCA-BIOLO-MACHOS & $107.0 \pm 30.65$ & COC, SOL,SALY HEMB.Y MAC & $\mathbf{9 . 8 2 6}$ & $\mathbf{0 . 0 0 3 ^ { * }}$ \\
COCA-BIOLO-HEMBRAS & $80,5 \pm 30.34$ & BIOLOGIC.ADOPTADOS, HEMBRASY MACHOS & 0.070 & 0.793 \\
COCA-ADOPTAD-MACHOS & $98,8 \pm 34.47$ & COC-SOL.SAL,BIOL-ADOPT,HEMBY MACHOS & 1.185 & 0.282 \\
COCA-ADOPTADO-HEMBRAS & $99,67 \pm 31.66$ & & & \\
\hline
\end{tabular}

En el tiempo de permanencia en los brazos abiertos se presentaron diferencias significativas en la comparación entre cocaína y Sol. Sal. en hembras y machos $F=9.826$ p: 0.003

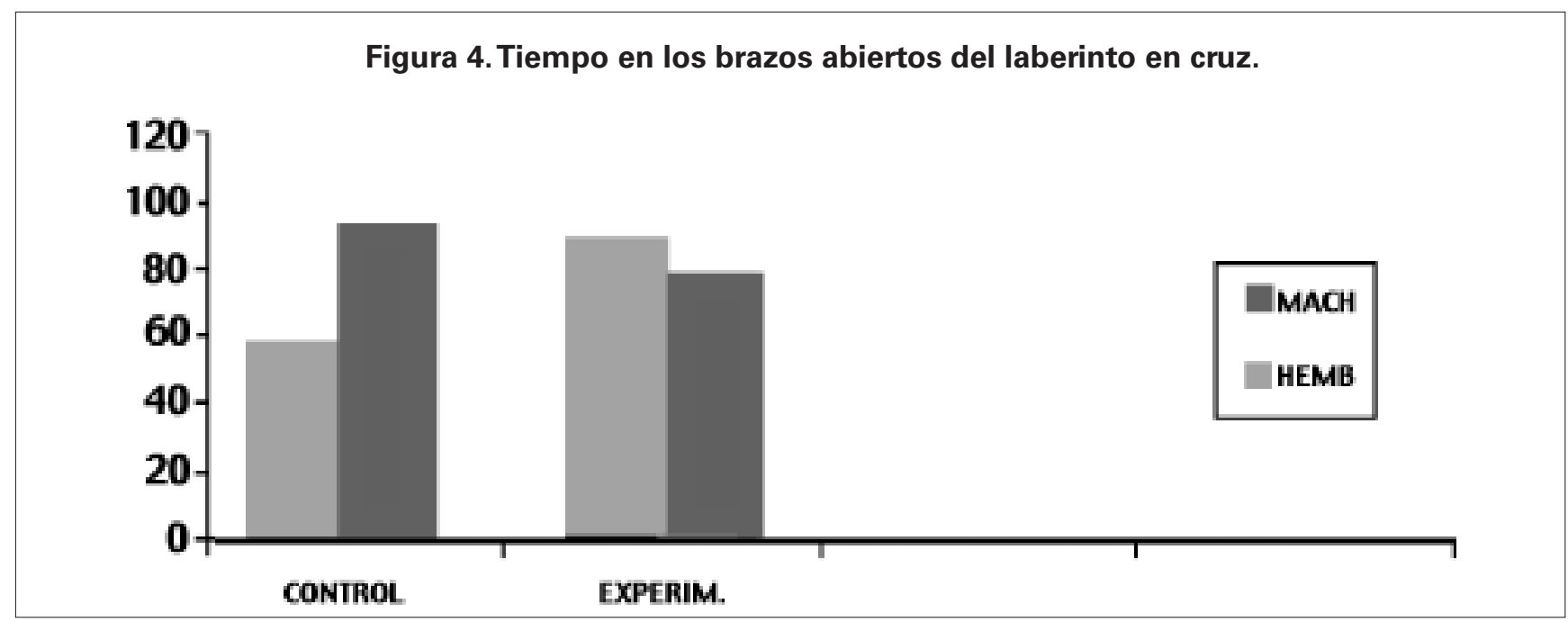

Se presenta el tiempo en los brazos abiertos de las hembras y los machos de los grupos
A continuación se presentan las comparaciones de los diferentes parámetros de conducta emocional entre la primera y la segunda observación.

\begin{tabular}{|lcc|}
\hline \multicolumn{3}{|c|}{ Tabla 7. Comparaciones entre la primera y segunda medición de Conducta Emocional } \\
\hline PARAMETROS & $\mathbf{T}$ & SIG \\
\hline ENTRADAS A LOS AGUJEROS & -0.812 & 0.420 \\
TIEMPO EN LOS AGUJEROS & -0.681 & 0.499 \\
ERGUIDAS & -0.267 & 0.791 \\
EXCRETAS & 1.709 & 0.093 \\
AUTOASEO & 1.364 & 0.179 \\
LOCOMOCION PERIFERICA & -0.055 & 0.957 \\
LOCOMOCION CENTRAL & 0.007 & 0.994 \\
LOCOMOCION TOTAL & -0.040 & 0.969 \\
ENTRADAS A BRAZOS CERRADOS & 1.632 & 0.109 \\
ENTRADAS A BRAZOS ABIERTOS & -0.764 & 0.449 \\
TIEMPO EN BRAZOS CERRADOS & $\mathbf{2 . 4 8 4}$ & $\mathbf{0 . 0 1 6 * *}$ \\
TIEMPO EN BRAZOS ABIERTOS & -1.098 & 0.277 \\
TIEMPO EN ZONA NEUTRA & -0.963 & 0.340 \\
\hline EXCRETAS EN EL LABERINTO EN CRUZ & 0.000 & 1.000 \\
\hline
\end{tabular}

Se encontró una disminución significativa del tiempo de permanencia en los brazos cerrados en la

segunda evaluación con una T=2.484 a una p> 0.016. 


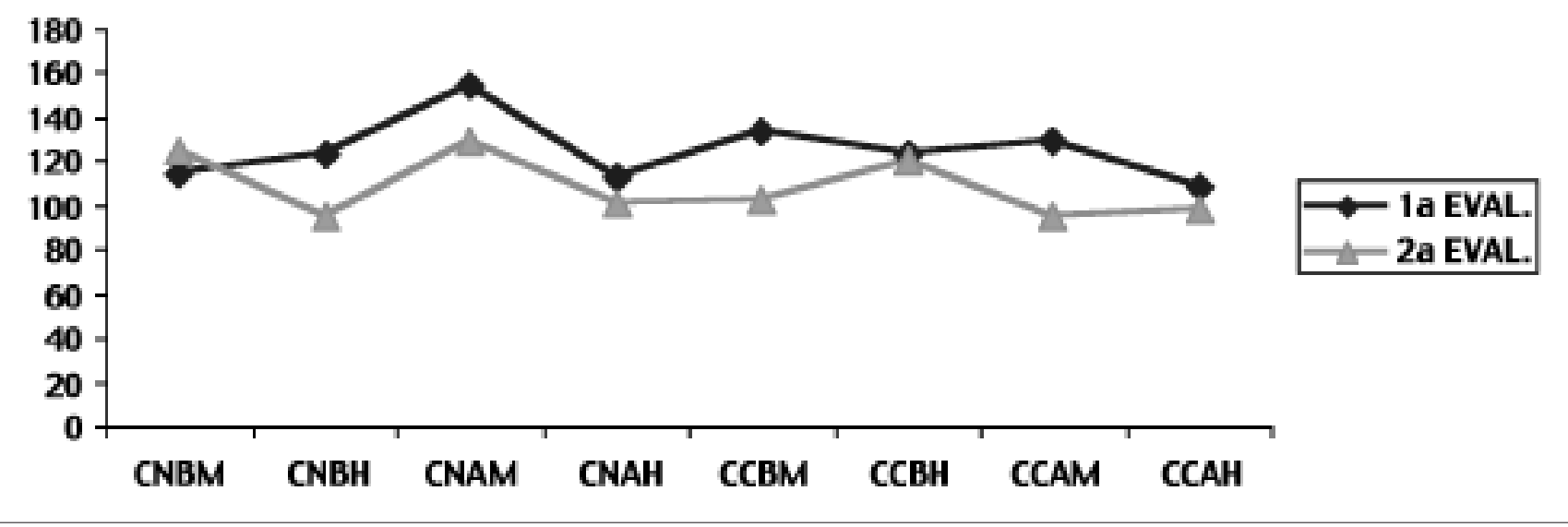

Se describe el Tiempo en brazos cerrados en los grupos tratados, en las dos evaluaciones con CC se refiere a los sujetos con tratamiento prenatal de coca- ína (30 mg/kg) y CN es el control, B se refiere a los hijos biológicos y $\mathrm{A}$ a los adoptados, $\mathrm{M}$ machos y con la $\mathrm{H}$ hembras.

\begin{tabular}{|c|c|c|c|c|c|c|c|}
\hline \multicolumn{8}{|c|}{ Tabla 8. Consumo de agua en $\mathrm{ml}$ en los hijos pretratados } \\
\hline $\begin{array}{l}0 \text { CONT/BIO } \\
\text { B MACH }\end{array}$ & $\begin{array}{c}\text { CONT/BIO/ } \\
\text { HEMBR }\end{array}$ & $\begin{array}{c}\text { CONT/ADO/ } \\
\text { MACH }\end{array}$ & $\begin{array}{c}\text { CONT/ADO/ } \\
\text { HEM }\end{array}$ & $\begin{array}{c}\text { COCA/BIO/ } \\
\text { MACH }\end{array}$ & $\begin{array}{c}\text { COCA/BIO/ } \\
\text { HEM }\end{array}$ & $\begin{array}{c}\text { COCA/ADO/ } \\
\text { MACH }\end{array}$ & $\begin{array}{c}\text { COCA/ADO/ } \\
\text { HEM }\end{array}$ \\
\hline $\begin{array}{l}\text { 1. } 10.5 \pm 2.74 \\
\text { 2. } 9.67 \pm 2.73 \\
\text { 3. } 11.17 \pm 4.07 \\
\text { 4. } 10.0 \pm 5.59 \\
\text { 5. } 10.7 \pm 7.53 \\
\text { 6. } 13.7 \pm 6.06 \\
\text { 7. } 9.5 \pm 2.43\end{array}$ & $\begin{array}{c}5,67 \pm 2.83 \\
5.33 \pm 2.16 \\
5.83 \pm 2.56 \\
3.83 \pm 1.72 \\
4.83 \pm 1.72 \\
9.33 \pm 5.05 \\
5.67 \pm 3.2\end{array}$ & $\begin{array}{c}9.0 \pm 2.53 \\
9.17 \pm 2.4 \\
8.33 \pm 4.96 \\
5.83 \pm 5.49 \\
8.83 \pm 4.96 \\
14.0 \pm 4.6 \\
9.67 \pm 2.66\end{array}$ & $\begin{array}{l}8.33 \pm 1.75 \\
9.17 \pm 3.37 \\
11.2 \pm 4.35 \\
6.83 \pm 2.64 \\
11.0 \pm 8.02 \\
11.5 \pm 5.32 \\
8.0 \pm 2.68\end{array}$ & $\begin{array}{c}8.33 \pm 1.21 \\
8.17 \pm 3.31 \\
5.83 \pm 2.48 \\
6.5 \pm 7.23 \\
6.67 \pm 5.57 \\
10.33 \pm 3.4 \\
7.83 \pm 3.43\end{array}$ & $\begin{array}{c}8.3 \pm 2.25 \\
9.1 \pm 2.48 \\
8.8 \pm 3.66 \\
8.67 \pm 4.3 \\
6.0 \pm 4.1 \\
12.8 \pm 5.8 \\
7.8 \pm 3.13\end{array}$ & $\begin{array}{l}8.33 \pm 2.25 \\
8.33 \pm 2.16 \\
6.67 \pm 1.96 \\
5.00 \pm 0.89 \\
6.50 \pm 4.51 \\
10.0 \pm 3.03 \\
6.33 \pm 2.42\end{array}$ & $\begin{array}{c}7.0 \pm 2.0 \\
8.0 \pm 2.1 \\
6.0 \pm 3.16 \\
8.33 \pm 2.88 \\
7.83 \pm 4.45 \\
14.2 \pm 5.46 \\
10.3 \pm 1.21\end{array}$ \\
\hline T $10.7 \pm 4.45$ & $5.79 \pm 2.76$ & $9.26 \pm 3.64$ & $9.43 \pm 4.02$ & $7.67 \pm 3.8$ & $8.8 \pm 3.67$ & $7.31 \pm 2.46$ & $8.81 \pm 3.04$ \\
\hline
\end{tabular}

\begin{tabular}{|lcccccc|}
\hline \multicolumn{7}{|c|}{ Tabla 9. Análisis Factorial del consumo de agua en los hijos tratados prenatalmente } \\
\hline 0 COCA.Y & BIOLO & HEMB.Y & COC..Y CON, & COCAY CON. & BIOL /ADOP & COC./ CON./BIOL \\
B CONTR. & Y ADOP & MACH & BIOL / ADOP & HEMB/ MACH & HEM /MACH & /ADOP, HEM/MACH \\
\hline 1. $F=1.108$ & $F=0.12$ & $F=9.109$ & $F=1.779$ & $F=4.143$ & $F=0.596$ & $F=3.079$ \\
$P>0.29$ & $P>0.727$ & $P>0.004^{* *}$ & $P>0.189$ & $P>0.48$ & $P>0.444$ & $P>0.086$ \\
2. $F=0.183$ & $F=0.972$ & $F=2.541$ & $F=2.809$ & $F=4.219$ & $F=1.141$ & $F=3.954$ \\
$P>0671$ & $P>0.33$ & $P>0.118$ & $P>0.101$ & $P>0.046^{*}$ & $P>0.291$ & $P>0.053$ \\
3. $F=6.361$ & $F=0.008$ & $F=0.970$ & $F=0.873$ & $F=3.879$ & $F=0.117$ & $F=3.569$ \\
$P>0.015^{* *}$ & $P>0.92$ & $P>0.330$ & $P>0.355$ & $P>0.055^{*}$ & $P>0.734$ & $P>0.065$ \\
4. $F=0.038$ & $F=0.593$ & $F=0.006$ & $F=0.0$ & $F=5.618$ & $F=1.813$ & $F=0.739$ \\
$P>0.847$ & $P>0.445$ & $P>0 . .941$ & $P>0.996$ & $P>0.22$ & $P>0.185$ & $P>0.395$ \\
5. $F=1.586$ & $F=0.97$ & $F=0.613$ & $F=0.176$ & $F=1.018$ & $F=2.183$ & $F=0,639$ \\
$P>0.215$ & $P>0.330$ & $P>0.438$ & $P>0.677$ & $P>0.318$ & $P>0.147$ & $P>0,428$ \\
6. $F=0.060$ & $F=0.657$ & $F=0.037$ & $F=0.198$ & $F=6.933$ & $F=0.383$ & $F=0,000$ \\
$P>0.808$ & $P>0.422$ & $P>0.849$ & $P>0.659$ & $P>0.012^{* *}$ & $P>0.539$ & $P>0,993$ \\
7. $F=0.0$ & $F=1.137$ & $F=0.860$ & $F=0.174$ & $F=12.413$ & $F=2.484$ & $F=1,040$ \\
$P>0.988$ & $P>0.292$ & $P>0.359$ & $P>0.679$ & $P>0.001^{* *}$ & $P>0.122$ & $P>0,313$ \\
\hline$T F=1.108$ & $F=0.123$ & $F=3.109$ & $F=1.779$ & $F=4.143$ & $F=0.596$ & $F=3.079$ \\
$O P>0.298$ & $P>0.727$ & $P>0.084$ & $P>0.189$ & $P>0.048^{*}$ & $P>0.444$ & $P>0.086$ \\
\hline
\end{tabular}


Fig. 6. Consumo de agua en hembras y machos en la primera observación.

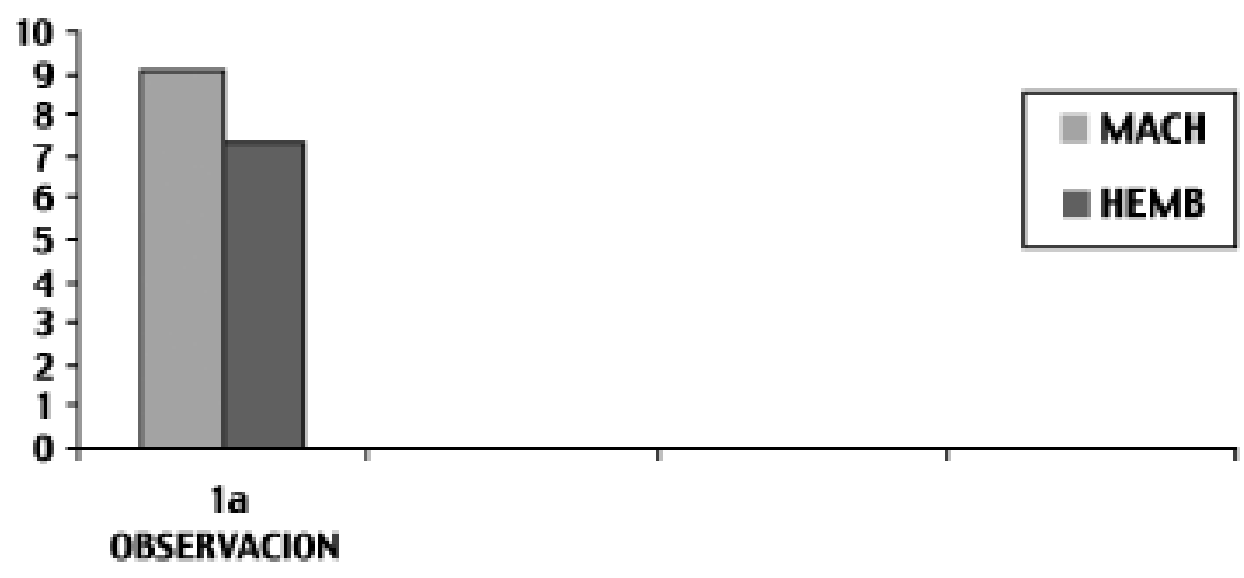

Figura 7. Consumo de hembras y machos de los grupos control y experimentales.

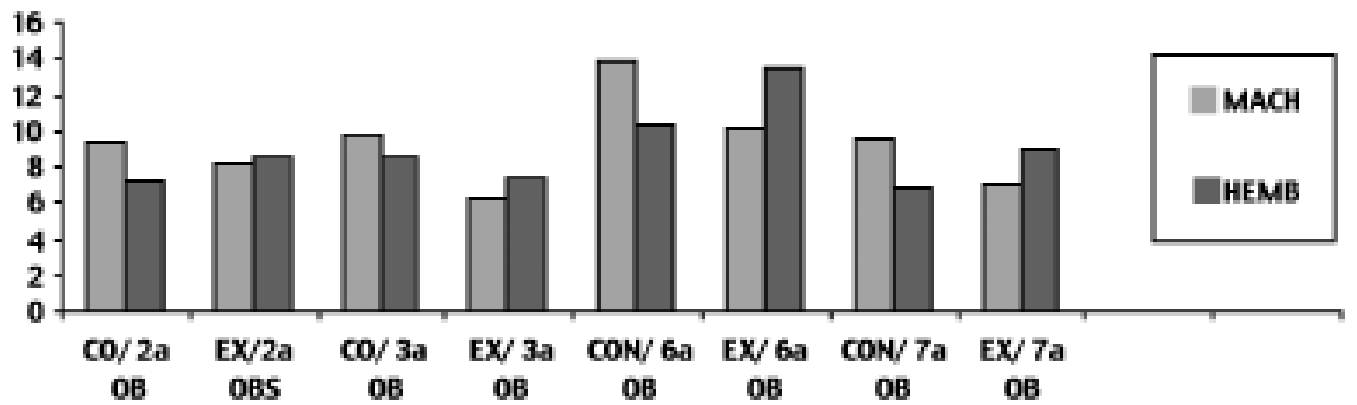

Se presenta el consumo de agua de las hembras y los machos del grupo control y experimental, además de la observación en la cual se encontraron diferencias significativas

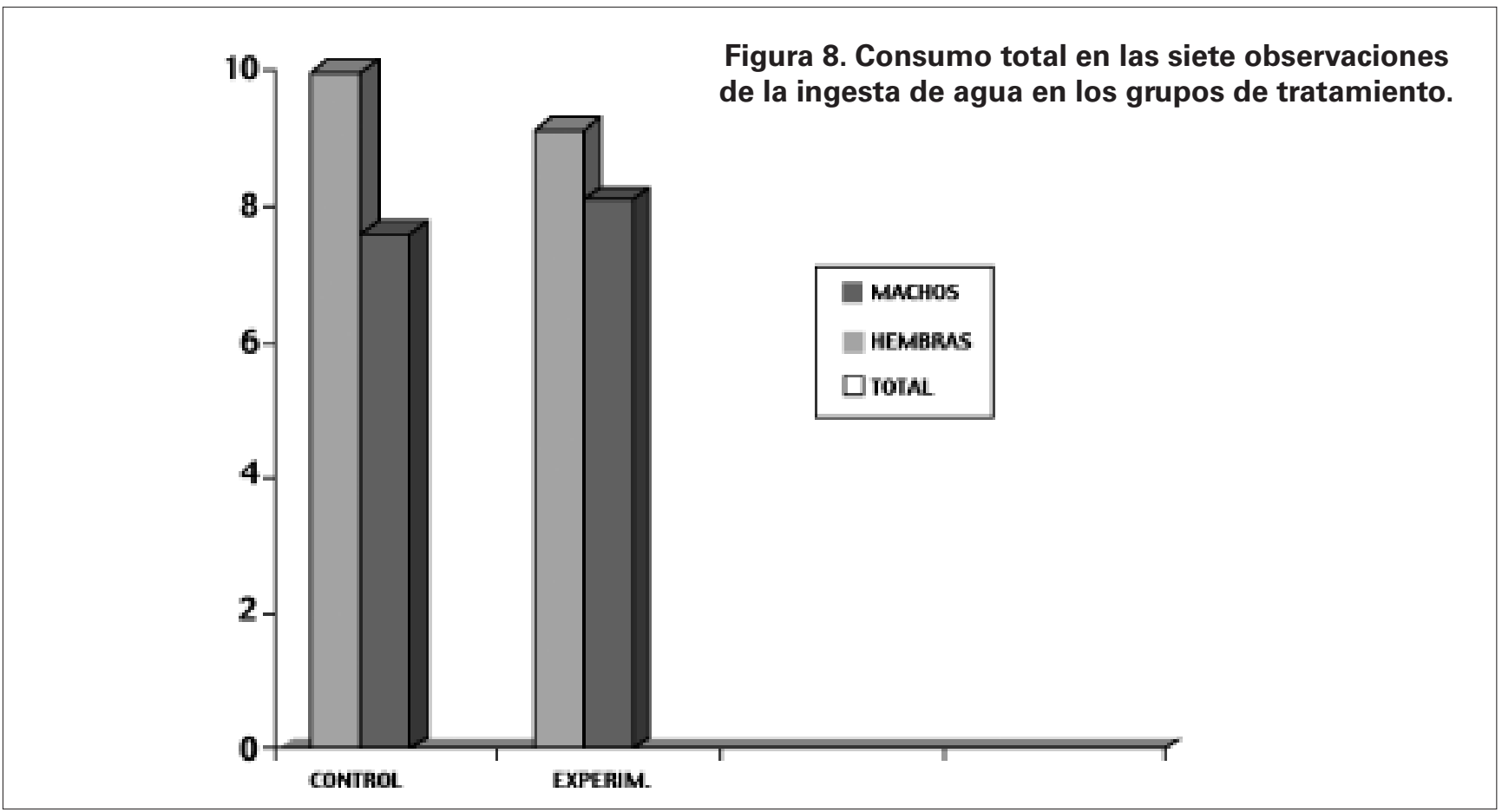


Tabla 9. Consumo de cocaína mediante el test de la escogencia libre, en $\mathrm{ml}$ de los hijos pretratados en época gestacional

\begin{tabular}{|c|c|c|c|c|c|c|c|c|}
\hline 0 & $\begin{array}{c}\text { CN CONT } \\
\text { BIOLO } \\
\text { MACH }\end{array}$ & $\begin{array}{c}\text { CN CONT } \\
\text { B BIOLO } \\
\text { H HEMBR }\end{array}$ & $\begin{array}{l}\text { CN CONT } \\
\text { A ADOPT } \\
\text { M MACH }\end{array}$ & $\begin{array}{l}\text { CN CONT } \\
\text { A ADOPT } \\
\text { H HEMBR }\end{array}$ & $\begin{array}{l}\text { CC COCAI. } \\
\text { B BIOLO } \\
\text { M MACH }\end{array}$ & $\begin{array}{c}\text { CC COCAI. } \\
\text { B BIOLO } \\
\text { H HEMBR }\end{array}$ & $\begin{array}{l}\text { CC COCAI. } \\
\text { A ADOPT } \\
\text { M MACH }\end{array}$ & $\begin{array}{l}\text { CC COCAI. } \\
\text { A ADOPT } \\
\text { H HEMBR }\end{array}$ \\
\hline 1 & $7.0 \pm 3.85$ & $6.33 \pm 1.97$ & $6.50 \pm 3.27$ & $6.33 \pm 2.5$ & $4,83 \pm 2.93$ & $5.50 \pm 2.88$ & $4,67 \pm 1.63$ & $8.5 \pm 2.88$ \\
\hline & $4.33 \pm 2.58$ & $4.5 \pm 2.17$ & $50 \pm 3.33$ & $5.67 \pm 2.7$ & $5.33 \pm 1.63$ & $4.33 \pm 2$. & $5.50 \pm$ & $6.17 \pm 2.48$ \\
\hline & $6.17 \pm 3.54$ & $6.67 \pm 4.59$ & $6.83 \pm 3.49$ & $9.5 \pm 5.47$ & $7.17 \pm 4.54$ & $5.17 \pm 2.04$ & $5.17 \pm 2.99$ & $4.83 \pm 1.33$ \\
\hline 4. & $4.17 \pm 2.86$ & $5.17 \pm 0.75$ & $6.17 \pm 2.93$ & $6.0 \pm 2.53$ & $6.0 \pm 2.28$ & $5.92 \pm 3.41$ & $5.17 \pm 3.31$ & $5.83 \pm 3.66$ \\
\hline 5 & $6.83 \pm 3.97$ & $8.16 \pm 6.01$ & $8.66 \pm 4.27$ & $6.83 \pm 8.51$ & $8.33 \pm 4.46$ & $8.33 \pm 5.53$ & $5.16 \pm 3.37$ & $7.5 \pm 5.01$ \\
\hline 6. & $9.0 \pm 5.18$ & $11.2 \pm 5.42$ & $10.7 \pm 4.46$ & $7.67 \pm 4.8$ & $9.33 \pm 5.61$ & $10.0 \pm 6.54$ & $6.33 \pm 5.32$ & $8.17 \pm 6.62$ \\
\hline 7. & $6.67 \pm 6.66$ & $6.83 \pm 3.71$ & $5.5 \pm 4.81$ & $8.0 \pm 6.13$ & $5.0 \pm 3.52$ & $5.83 \pm 3.87$ & $5.67 \pm 1.37$ & $4.33 \pm 3.01$ \\
\hline T & $6.31 \pm 4.09$ & $6.98 \pm 3.52$ & $7.26 \pm 3.79$ & $7.14 \pm 4.67$ & $6.57 \pm 3.57$ & $6.44 \pm 3.76$ & $5.38 \pm 3.47$ & $6.48 \pm 3.57$ \\
\hline
\end{tabular}

Como se puede apreciar en la tabla anterior no se presentaron diferencias en el consumo de Cocaína 30 $\mathrm{mg} / \mathrm{kg}$ en los diferentes grupos de tratamiento.

\section{CONCLUSIONES}

En el presente estudio no se encontraron efectos de la administración prenatal de cocaína $(30 \mathrm{mg} / \mathrm{kg})$; durante 20 dias consecutivos (administración crónica) ni de las condiciones de crianza en la conducta emocional de los ratones adultos jóvenes hembras y machos, porque no hubo variaciones importantes en ninguno de los parámetros de la caja de agujeros y del laberinto en cruz, ni en las hembras ni en los machos en la primera evaluación de la CE - realizada en las primeras cinco semanas de edad.

Posteriormente, se sometió a los sujetos al paradigma de la "elección libre de dos botellas ", y no se encontraron diferencias en el consumo voluntario de hidrato de cocaína entre los sujetos del estudio, por lo tanto el tratamiento prenatal con cocaína $(30 \mathrm{mg} / \mathrm{kg}$ ) ni las condiciones de crianza (Adoptado vs. Biológico) tuvieron influencia en el posterior consumo voluntario de cocaína (30 mg/kg) en ratones hembras y machos; aunque en un estudio anterior (Santacruz, Maldonado y Rodríguez, 2000) los ratones adultos con tratamiento prenatal crónico de cocaína $(20 \mathrm{mg} / \mathrm{kg}$ ) presentaron un significativo mayor consumo de cocaína oral (30 $\mathrm{mg} / \mathrm{kg}$ ) en comparación a los del grupo control y aunque la cronicidad de la aplicación fue la misma (20 días consecutivos durante el periodo de gestación), lo que sugiere la existencia de algunos factores ambientales relacionados que no se han determinado en el presente estudio y que podrían estar influyendo en el no -consumo diferencial de cocaína en los hijos de madres adictas.

Se observo durante siete días consecutivos el consumo de agua en mililitros, se encontró consumo dife- rencial relacionado con la administración prenatal de cocaína $(30 \mathrm{mg} / \mathrm{kg}$ ) en hembras y machos en 4 observaciones y en el total. La hembras del grupo control en general consumieron menos agua que los machos en todas las observaciones donde hubo diferencias significativas, pero las hembras del grupo expuesto a la cocaína in útero consumieron significativamente mayor cantidad de agua que los machos prenatalmente tratados con cocaína $(30 \mathrm{mg} / \mathrm{kg}$ ); por lo tanto las hembras fueron mas ansiosas que los machos prenatalmente tratados con cocaína $30 \mathrm{mg} / \mathrm{kg}$, al consumir mayor cantidad de agua. Los machos con tratamiento prenatal presentan menor consumo que los del grupo control, la menor ingesta de agua esta relacionada con menor ansiedad; De esta forma se puede observar que el fármaco afecto diferencialmente a las hembras y a los machos (en relación al género); las hembras fueron mas ansiosas que los machos, por lo que se podría suponer que la cocaína $(30 \mathrm{mg} / \mathrm{kg}$ ) prenatal altera la CE de las hembras, volviendolas mas emotivas, en cambio a los machos los vuelve mas tranquilos las condiciones de crianza no influyeron en esta conducta.

Además, hay que tener en cuenta que en los siete días consecutivos, en que se evaluaba el consumo voluntario de agua y cocaína, se esperaba que los machos estubieran mas ansiosos porque estaban en condiciones gregarias de mantenimiento, durante el tiempo suficiente para definirse las jerarquías sociales, situación que les genera mayor ansiedad debido a que estas se definen a través de constantes agresiones, las que cesan una vez se se discrimine el macho alfa del grupo. Pero contrario a lo esperado, los machos exhibieron menor ansiedad que el grupo control y que las hembras, reflejada en el menor consumo de agua.

Estas diferencias de la emocionalidad relacionadas al género se corroboran en otros estudios donde se han encontrado comportamientos diferenciales en hembras y machos (Fernandez-Teruel,, Escorihuela, 
Driscoll, Tobeña, y Batting, 1992; Blanchard, Blanchard, De Padua, Veniegas, Rodger, y Shepherd,1992) y el uso de fármacos acentúan estas diferencias, lo que se ha afirmado constantemente a traves de numerosos estudios de laboratorio y también en diferentes estudios epidemiológicos (Gilbert, Knasko, Sabini,1997). Las hembras generalmente son más emotivas que los machos y reaccionan mas lentamente al estrés, de igual forma la recuperación a una situación ansiogénica es mas lenta, las hembras presentan mayor tiempo de congelamiento y mas chillidos en comparación a los machos y se ven mas afectadas por lo efectos farmacológicos, por lo tanto se puede decir que presentan mayor vulnerabilidad al fármaco. (Fernandez-Teruel,, Escorihuela, Driscoll, Tobeña, y Batting, 1992; Blanchard, Blanchard, De Padua, Veniegas, Rodger, y Shepherd, 1992; Hughes, Donohue, Dow-Edwards, 1996)

Este incremento en el consumo de agua, de las hembras, podría explicarse por una posible subsensibilidad a la cocaína, como efecto del tratamiento prenatal y que esta subsensibilidad se manifiesta por el consumo voluntario de cocaína $30 \mathrm{mg} / \mathrm{kg}$, (en siete días) aunque en el consumo de cocaína oral no se presentaron diferencias entre los grupos de estudio, así dosis mínimas de este fármaco, permiten que se detecten diferencias importantes en la ingesta de agua.

En la segunda medición de Conducta Emocional (a las 7 semanas de edad) se encontraron diferencias importantes en cuatro parámetros de conducta exploratoria. Las diferencias basicas estuvieron entre las hembras y los machos, con los cuales interactuaron el tratamiento prenatal o las condiciones de crianza.

Los machos tratados prenatalmente con la droga son mas exploradores en las áreas abiertas e iluminadas, permaneciendo mayor tiempo en este sitio, lo que les facilita los brazos abiertos del laberinto en cruz a diferencia de las hembras prenatalmente tratadas quienes exploraron significativamente menos los brazos abiertos; de tal forma que los machos con tratamiento prenatal con cocaína exhiben conductas de mayor tranquilidad en contraposicion a las hembras quienes se muestran significativamente más ansiosas.

Indices que se corroboran con las exploración en los brazos cerrados, donde similarmente las hembras ocupan mas tiempo los brazos cerrados, menor exploración, índice de mayor ansiedad, porque permanecian mayor tiempo en las áreas oscuras, protegiéndose de un posible "depredador". Así en la segunda evaluacion de conducta emocional, en el laberinto en cruz, se encuentra una gran influencia del tratamiento prenatal con la cocaína (30 mg/kg) y estos efectos son genero/relacionadas; las hembras fueron mas ansiosas o emotivas y los machos menos ansiosos y mas exploradores.

En cuanto a la locomoción central, se encontro que afectaron mas las condiciones de crianza en las hem- bras y los machos, así los machos criados con sus madres biológicas fueron mas ansiosos, porque exhibieron menor exploración, en contraposición a las hembras mantenidas con sus madres biológicas, las cuales exploraron más el centro del tablero de agujeros, área mas clara y desprotegida. El complemento de estos dos modelos de conducta exploratoria fue muy efectivo para evaluar los efectos de la droga prenatal y de las condiciones ambientales tempranas que rodearon en recién nacido.

Aunque las hembras exhibieron menor autoaseo que los machos, no se encontraron efectos ni del tratamiento prenatal, ni de las condiciones de crianza, lo que se atribuye a las diferencias comportamentales relacionadas al género, lo cual es evidente en todos los animales incluidos dentro de la escala filogenética.

Se encontraron diferentes alteraciones a largo plazo (segunda evaluación de conducta emocional) por el tratamiento farmacológico prenatal y la crianza en la Conducta Emocional, en las hembras y machos adultos; dichas alteraciones fueron en dos importantes índices de ansiedad evaluados en el laberinto en cruz, como es el tiempo de permanencia en los brazos abiertos y cerrados. En el tablero de agujeros se hicieron más evidentes los efectos de las condiciones de crianza, pero con efectos opuestos en las hembras y los machos; los machos mantenidos con sus madres biológicas fueron menos exploradores que los adoptados, con las hembras se observo lo contrario: las que se mantuvieron con sus madres biológicas se mostraron mas tranquilas y exploradoras en comparación a las adoptadas, evaluadas en un índice importante del tablero de agujeros, como es la locomoción central.

Esta influencia diferencial de las condiciones de crianza en los machos y hembras adultos, que se encontró gracias al tablero de agujeros, podría hacer pensar en que existen interacciones maternas diferentes con las crías hembras y machos, lo que se ha encontrado en algunos estudios las madres exhiben mayor lamido anogenital a los machos que a las hembras, (Baum, Bressler, Daum, Veiga, McNamee,1996; Cladji, Tannenbaum, Sharma, Francis, Plotsky, and Meaney, 1998) así las madres biológicas podrían haber prestado menor atención de la usual a los machos, causando alteraciones en su emocionalidad en adultos y a las hembras mayor atención, lo cual posiblemente les serviría para programar las respuestas de ansiedad. Las hembras exhibieron mayor conducta exploratoria en adultas lo que se correlaciona positivamente con tranquilidad. No se tienen datos relacionados con la conducta materna diferencial para hembras y para machos en el presente estudio por lo tanto, se resalta que es un aspecto importante de explorar próximamente.

En el tiempo de exploración en los brazos abiertos, las hembras exploran menos tiempo que los machos; estos efectos diferenciales relacionados con el género 
se deban a la subsensibilización a la cocaína (30 $\mathrm{mg} / \mathrm{kg}$ ), como producto del tratamiento prenatal y ante el consumo de hidrato de cocaína se hagan evidentes los efectos ansiolíticos en los machos, aunque el consumo fué mínimo, y los efectos de este consumo sean diferentes para las hembras -ansiogénicos-, esto se ha corroborado usando otras drogas en gestación, como Domínguez, López, Chotro, Molina (1996) quienes encontraron que la intoxicación materna al alcohol durante los últimos días de gestación, facilitan una exposición fetal a los atributos quimosensoriales del alcohol, lo que modifica la responsividad posterior a las señales del alcohol, determinándose la gestación como un período especialmente crítico para la subsensibilidad a los efectos del alcohol, y Hughes, Donohue, Dow-Edwards(1996) encontraron una subsensibilización causada por la cocaína prenatal a los efectos de las afetaminas. En el presente estudio no se evalúo la posible subsesibilización que podrían causar el tratamiento farmacológico prenatal, porque todos los sujetos fueron sometidos al consumo voluntario de cocaína oral, lo que queda como una hipótesis a comprobar proximamente.

En cuanto a las comparaciones entre la primera y la segunda evaluación de la conducta emocional, se encontró menor tiempo en los brazos cerrados todos los grupos del estudio en la segunda observación, lo que se puede interpretar como una reducción en los niveles de ansiedad, como producto de la maduración de los sujetos en general, mas que por el tratamiento prenatal con la droga o por las condiciones de crianza.

Al encontrarse diferencias entre diversos parámetros de la conducta emocional en la segunda evaluación, se infiere que los efectos tanto del tratamiento farmacológico prenatal como de las condiciones de crianza (madre biológica o nodriza) se manifiestan a más largo plazo y podrían potenciarse por el uso de la cocaína oral, posiblemente por la subsensibilización del tratamiento farmacologico prental; estos efectos diferenciales relacionados al genero se han encontrado en varios índices conductuales evaluados en el presente estudio. Una vez mas se observa como las circustancias ambientales prenatales como el la exposición a la cocaína in útero son críticas para el establecimiento de las respuestas del adulto a las situaciones de estrés.

Aunque se evaluaron numerosos indices de conducta emocional, en dos momentos a corto y a largo plazo en los sujetos del presente estudio, la falta de efectos farmacológicos y de crianza observados en la primera evaluación de la conducta emocional, se podrían atribuir a la estimulación posnatal, como una experiencia neonatal temprana de gran importancia, porque al grupo tratado prenatalmente con cocaína, desde épocas tempranas de nacimiento se estimularon diariamente, porque ante la necesidad de distinguir los hijos biológicos de los adoptados, los farmacologicamente tratados se marcaban diariamente, lo que genereraba mayores contactos de los experimentadores con los sujetos, ademas de mayor lamido por parte de la hembra madre, para limpiar las crías de la marca realizada, de tal manera que este manejo casual pudo ser uno de los factores que contribuyó a atenuar los efectos causados por el tratamiento prenatal: Asi es posible que esta experiencia neonatal temprana, podría atenuar los efectos farmacológicos, ya que se ha encontrado reiteradamente la gran importancia de la estimulación posnatal temprana; en la formación de comportamientos adaptativos en el adulto; Los animales manipulados en períodos neonatales tempranos exhiben conductas emocionales adecuadas y una suceptibilidad reducida a la desesperanza aprendida (Tejedor-Real, Costela, Gilbert-Rahola, 1997); Weinberg, Kim, Know y Yu (1995) encontraron que la manipulación temprana eliminaba algunos efectos de la exposición al alcohol in útero.

Por eso se explorarán posteriormente los efectos de la estimulación posnatal temprana en la reversión o atenuación de los problemas causados por la exposición prenatal a la cocaína, ya que el indagar acerca de este manejo ambiental podria ayudar al conocimiento de una alternativa de manejo para los infantes lesionados por el consumo materno.

Los resultados encontrados en la ingesta de agua, en los grupos de tratamiento son similares a los arrojados por los diferentes indices de conducta exploratoria, esto afirma que la combinación de estos modelos permite una exploración amplia y adecuada de la conducta emocional., entonces se puede hacer un analisis exaustivo y obtener lo máximo de información de esta conducta, porque al observarse desde diferentes situaciones se obtiene información relevante acerca de cómo el animal maneja su hábitat, así el uso de parámetros de exploración asociados al tablero de agujeros y al laberinto en cruz, complementados con la evaluación de la ingesta voluntaria de agua, permiten el conocmiento detallado de las habilidades de manejo ambiental del sujeto y que se relacionan directamente con la supervivencia.

Otro aspecto positivo del presente trabajo es la observación en dos momentos diferentes la conducta emocional, mediante estas dos evaluaciones se pueden percibir si los efectos se manifiestan o se mantienen a largo plazo, además de la combinación con el consumo voluntario de cocaína permite detectar efectos prenatales de sensibilización a la cocaína y/o también la vulnerabilidad a la droga.

El presente estudio permite conocer algunos factores relacionados con la administración prenatal y el posterior desenvolvimiento conductual de los hijos, pero también ha ayudado a generar hipótesis explicativas de otras variables que pueden estar influyendo en estos resultados y que son los aspectos en los que se enfocaran las siguientes investigaciones, como los 
efectos de la manipulación en la atenuación de las alteraciones producidas por el tratamiento prenatal en la conducta emocional, y que puede generar estrategias que guíen el tratamiento y/o la prevención de futuros trastornos conductuales causados por conductas parentales.

\section{BIBLIOGRAFÍA}

Baum, MJ., Bressler, SC., Daum, MC., Veiga, CA., Mc Namee, CS (1996)Ferret mothers provide more anogenital licking to male offspring: possible contribution to psychosexual differentiation. Physiology Behavior. 60(2): 353-9.

Bernard, J.F., Bandler, R. (1998) Parallel circuits for emotional coping behaviour: New pieces in the puzzle. Journal of Comparative Neurology. Vol. 401, no. 4, pp. 429-436.

Blanchard, C., Blanchard, R., De Padua, A., Veniegas, R., J., Rodger, J. y Shepherd, J. (1992) MK-801 produces a reduction in anxiety-relates antipredator defensiveness in male and female rats and gender-dependent increase in locomotor behavior. Psychopharmacology. 108:352-362.

Bland-Stewart, L.M., Seymour, H.N., Beeghly, M. y Frank, D.A.(1998) Semantic development in African-American children prenatally exposed to cocaine. Semin Speech Language. 19 (2):167-86.

Carlos, E.A. (1998) A prospective longitudinal study of attachment disorganisation / disorientation. Children Development. Aug, 69(4) 1107-28.

Carter, B.L. (1989) A counselling the pregnant or lactating patient. ASHP-Midyear-Clinical-Meeting; 1989; 24 (Dec); 43-60.

Carter, C.S., Lederhndler, P. y Kirkpatrick, B. (1997) The integrative neurobiology of affiliation. Introduction. Annual New York Academy Sciences. Jan 15, 807 xiiixviii.

Chasnoff, I. J.(1992) Cocaine Pregnancy and growing child. In current problems in paediatrics. Chicago: Mosby Yearbooks.

Chen, W.J., Andersen, K.H., West, J.R. (1994) Alcoholinduced brain growth restrictions (microencephaly) were not affected by concurrent exposure to cocaine during the brain growth spurt. Teratology. Sep; 50(3): 250-5.

Clement,Y., Chapouthier, G. (1998) Biological bases of anxiety. Neuroscience and Biobehavioral Reviews. vol. 22, no. 5, pp. 623-633.

Cortese, B.M., Krahl, S.E., Berman, R.F., Hannigan, J.H. (1997) Effects of prenatal ethanol exposure on hippocampal theta activity in the rat. Alcohol. vol. 14, no. 3, pp. 231-235.

Claro, F., Perez-lzquierdo, M.A., Del-Abril, A., Segovia, S., Guillamon, A., Del-Cerro, M.C. (1994) MBR: a computer programs to record and analyse parental behavior in rodents. Physiology Behavior. Nov 56(5). 1069-73.

Cladji, C., Tannenbaum, B., Sharma, S., Francis, D., Plotsky, P. M. and Meaney, M. J. (1998) Maternal care during infancy regulates the development of neural systems mediating the expression of fearfulness in the rat. Processes Natal Academy Science USA. 28, 95(9) 5335-40.

D'amato, F.R., Cabib, S., Ventura, R. Orsini, C.(1998) Longterm effects of posnatal manipulation on emotionally are prevented by maternal anxiolytic treatment in mice. Development Psychobiology. 32, 225-34.

Dess, N. K. (1991) Ingestion and emotional health. Human Nature. 2, 235-269.

Dess, N. K. y Minor, T. R and Brewer, J. (1989) Suppression of feeding and body weight by inescapable shock: modulation by quinine adulteration, stress reinstatement and controllability. Physiology and Behavior, 45,975-983.

Dess, N.K. y Chapman, C.D. (1990) Individual differences in taste. Body weight and depression in the helplessness rat model and in humans. Brain Research Bulletin. 24, 669-676.

Diaz, J.L. (1985) Análisis estructural de la conducta. Universidad Nacional Autónoma de Mexico. Dirección general de publicaciones. Mexico D. F.

Dominguez,H.D., Lopez,M.F., Chotro,M.G., Molina, J.C. (1996) Perinatal responsiveness to alcohol's chemosensory cues as a function of prenatal alcohol administration during gestational days 17-20 in the rat. Neurobiology Learn and Memory vol. 65, no. 2, pp. 103-112.

Dutriez-Casteloot, I., Bernet, F., Dedieu, J.F., Croix, D., Laborie, C., Montel, V., Lesage, J. Beauvillain, J.C., Dupouy, J.P. (1999) Hypothalamic-pituitary-adrenocortical and gonadal axes and sympathoadrenal activity of adult male rats prenatally exposed to morphine Neuroscience-Letters [Neurosci.-Lett.] 1999 vol. 263, no. 1, pp. 1-4.

Ellsworth, JA., Andersen, C. (1997) Adoption by captive parturient rhesus macaques: Biological vs. adopted infants and the cost of being a "twin" and rearing "twins". American Journal of Primatology. 43, 259-64.

Fernandez-Teruel, A., Escorihuela, R., Driscoll, P., Tobeña, A., \& Batting, K. (1992) Differential effects of early stimulation and/or perinatal flumazemil treatment in young Roman Low and Hight avoidance rats. Psychopharmacology. 108, 170-176.

Fiala, B., Snow, F.M., Greenought, W.T. (1977) Impoverished Rats Weigh More than Enriched rats because they eat more. Development Psychobiology. 10:537-541.

Field T.(1998) Maternal depression effects on infants and early interventions. Prevention Medical. March- Abril, 27 (2): 200-3.

Flint, J., Corley, R., DeFries, J.C., Fulker, D.W., Gray, J.A., Miller, S., Collins, A.C.A (1995) simple genetic basis for a complex psychological trait in laboratory mice. Science Wash. vol. 269, no. 5229, pp. 1432-1435.

Goodwin, G.A., Bliven, T., Kuhn, C., Francis, R., Spear, L.P. (1997) Immediate early gene expression to examine neuronal activity following acute and chronic stressors in rat pups: Examination of neurophysiological 
alterations underlying behavioral consequences of prenatal cocaine exposure. Physiology Behavioral. vol. 61, no. 6, pp. 895-902.

Gouldsboroug, Y., Black, V., Johnson, I.T. Asthon, N.(1998) Maternal nursing behavior and delivery of milk to the neonatal spontaneously hipertensive rat. Acts Physiology Scandinavia. 162, 107-14.

Hecht, G.S., Spear, N.E., Spear, L.P. (1998) Alterations in the reinforcing efficacy of cocaine in adult rats following prenatal exposure to cocaine. Behavioral Neuroscience. vol. 112, no. 2, pp. 410-418.

Hendrie, C.A., Weiss, S.M., Eilam, D. (1996) Exploration and predation models of anxiety: Evidence from laboratory and wild species. Pharmacology Biochemical Behavioral. vol. 54, no. 1, pp. 13-20.

Hill, S Y., y Poewell, B.J. (1976) Cocaine and Morphine SelfAdministration: Effects of Differential Rearing. Pharmacology Biochemical Behavior. 5: 701-704.

Hughes, HE., Donohue, LM., Dow Edwards, DL.(1996) Prenatal cocaine exposure affects the acoustic startle response in adult rats. Behavior Brain Research. vol. 75, no. 1-2, pp. 83-90.

Insel, TR., Winslow, JT., Wang, ZX., Young, L., Hulihan, T.J.(1995) Oxytocin and the molecular basis of monogamy. Advanced in Experimental Medicine Biological. 395: 227-34.

Jansson, L., Svikis, D, Lee J., Paluzz, P., Rutligiano, P. and Hackerman, F.(1996) Pregnancy and Addiction. Journal of Substance Abuse Treatment, 13, 321-329.

Jones, S. y Brain, P.(1985) An illustration of simple sequence analysis with reference to the agonistic Behavior of four trains cepas Sprains of laboratory mouse. Behavior processes. 11, 365-388.

Kosofsky, B.E. (1998) Cocaine-induced alterations in the neuro-development. Seminary speech-language. 19, 109-21.

Kurnianto, E., Shinjo, A. y Suga, D. (1998) Prenatal and posnatal maternal effects on body weight in crossfostering experiment on two subspecies of mice. Experimental Animal. 47, (2) 97-103.

Laviola, G., Petruzzi, S., Rankin, J., and Alleva, E. (1994) Induction of maternal behavior by mouse neonates: influence of dam parity and prenatal oxazepam exposure. Pharmacology and Biochemical Behavior. Dec; 49(4): 871-6.

Lidow, M.S. (1995) Prenatal cocaine exposure adversely affects development of the primate cerebral cortex. Synapse. vol. 21, no. 4, pp. 332-341.

Matera, C. Warren, W., Moomjy, M., Find, D. and Fox, H. (1990) Prevalence of the use of cocaine and other substances in an obstetric population. American Journal of obstetric and gynaecology. 163, 797-801.

McElhatton, P.R.(1994) The effects of benzodiazepine use during pregnancy and lactation. Reproduction Toxicology. Nov-Dec; 8(6): 461-75.

Niesink, R.J.M., Vanderschuren, L.J.M.J., Van-Ree, J.M. (1996). Social play in juvenile rats after in utero exposure to morphine. Neurotoxicology. vol. 17, no. 3-4, pp. 905-912.

Panksepp, J., Nelson, E., Siviy, S. (1994) Brain opioids and mother-infant social motivation. Acta Paediatrics Supply. Jun 397. pp 40-6.

Perez A. y Correa, E. (1994) Consumo de sustancias Psicoactivas en Santa Fe de Bogotá: Alcaldía Mayor de Bogotá: Unidad Coordinadora de Prevención Integral. Colombia. Guadalupe.

Plan Municipal de prevención en Medellin (1994) Hospital Universitario de San Vicente de Paul: Departamento de toxicología. Alcaldia de Medellin. Compendio de farmacología y alcoholismo. Medellin. Colombia.

Prasad, A., Henry, M., Prasad, C. (1996) Heterogeneity in the performance of outbreed Sprague-Dawley rats in an elevated-plus maze test: A possible animal model for anxiety disorder. Life Sciences. vol. 59, no. 18, pp. 1499-1506.

Rex, T., Voigt, H., Voits, H. and Fink, F. (1998) Pharmacological Evaluation of a Modified Open-Field Test Sensitive to Anxiolytic Drugs. Pharmacology Biochemistry and Behavior. vol. 59, no. 3, pp. 677-683.

Ritz, MC. Garcia, J.M., Protz, D., Rael, AM y George, F.R. (1994) Ethanol reinforced behavior in P, Np, HAD y LAD rats: Different genetic regulation of reinforcements and motivation. Behavioral Pharmacology. 5, 521-531.

Rodgers, R.J., Cao, B.J. Dalvi, A., Holmes, A (1997). Animal models of anxiety: An ethnological perspective. Brazilean Journal Medical Biology Research. vol. 30, no. 3, pp. 289-304.

Rodriguez, E., Duque, L. Y Rodriguez, J (1993) Estudio Nacional sobre consumo de Sustancias Psicoactivas en Colombia. 1992. Dirección Nacional de estupefacientes. Minijusticia. Fundación Santa Fe de Bogotá. Fundación Escuela Colombiana de Medicina.

Rosenblatt, J.S.(1994) Psychobiology of maternal behavior: contribution to the clinical understanding of maternal behavior among humans. Acta Paediatrics Supply. Jun; 397: 3-8.

Rosenblatt, J.S., Wagner, C.K., Morrell, JI.(1994) Hormonal priming and triggering of maternal behavior in the rat with special reference to the relations between estrogen receptor binding and ER mRNA in specific brain regions. Psychoneuroendocrinology. 19 (5-7): 543-52.

Santacruz, M. P. (1998) Línea de investigación en psicofarmacología de la cocaína y el alcohol en ratas y ratones. Acta Colombiana de Psicología. 1,71-103.

Silverman, M. (1976) Animal Behavior, the rat in laboratory. New York: Lancet.

Smith, J., Neil, J.C. y Costall, B. (1997) Post-waning housing conditions influence the behavioral effects of cocaine and d-amphetamine. Psychopharmacology. 131, 23-33.

Smith, J.K. Neil, J.C. y Costall, B. (1997) Bi-directional Effects of Dopamine D2 receptor antagonists on responding for a conditioners Reinforce. Pharmacology Biochemistry Behavior. 57, 843-849.

Wang-MW; Crombie DL., Mais, DE., Hayes, JS., Heap, RB (1995) Anti-progesterone antibody administration and 
the impairment of postpartum maternal care in mice. Journal of Endocrinology. May; 145(2): 363-9.

Weinberg, J., Kim, C., Kwon, P. and Yu, W. (1995). Early handling can attenuate adverse effects of fetal ethanol. Alcohol. vol. 12, no. 4, pp. 317-327.

Weinberg, M.K. y Tronick, E.Z.(1998) The impact of maternal psychiatric illness on infant development. Journal Clinical Psychiatry. 59 (2) 53-61.

Wilson, A. Neil, J. and Costall, B. (1996) The 5-HT1a Receptor agonist 8-OH- DPAT reduces ethanol intake and maintained behavior in female Sprague-Dawley Rats(1996) Alcohol 13 407-413.

Yirmiya, R., Tio, D.L., Taylor, A.N. (1996). Effects of fetal alcohol exposure on fever, sickness behavior, and pituitary-adrenal activation induced by interleukin-1 beta in young adult rats. Brain Behavior Immunology. vol. 10, no. 3, pp. 205-220.

Tejedor-Real, P., Costela, C., Gilbert-Rahola, J. (1997) Neonatal handling reduces emotional reactivity and susceptibility to learned helplessness. Involvement of catecholaminergic systems. Life Sciences. 62, 1, pp.37-50.

Torres de Galvis, M y Murelle, F.(1987) Estudio Nacional sobre alcoholismo y sustancias que producen dependencia. Medellin. Universidad de Antióquia. Facultad de salud Pública.

Weinraub, Z., Bental, Y., Olivan, A., Rotchild, A. (1998) Neonatal withdrawal syndrome and behavioral effects produced by maternal drug use. Addiction Biology. Vol. 3, pp 159-170. 